\title{
Role of lymphatic endothelial cells in the tumor microenvironment-a narrative review of recent advances
}

\author{
Miao He ${ }^{1 \#}$, Qihua He ${ }^{1,2 \#}$, Xiuyu Cai ${ }^{3 \#}$, Zisheng Chen ${ }^{1,4}$, Shen Lao ${ }^{1}$, Hongsheng Deng ${ }^{1}$, Xiwen Liu ${ }^{1}$, \\ Yongmei Zheng ${ }^{1}$, Xiaoyan Liu ${ }^{1}$, Jun Liu ${ }^{1}$, Zhanhong Xie ${ }^{1,5}$, Maojin Yao ${ }^{1}$, Wenhua Liang ${ }^{1,6}$, Jianxing He $^{1}$ \\ ${ }^{1}$ Department of Thoracic Surgery, China State Key Laboratory of Respiratory Disease and National Clinical Research Center for Respiratory \\ Disease, The First Affiliated Hospital of Guangzhou Medical University, Guangzhou, China; ${ }^{2}$ Department of Oncology, The First Affiliated \\ Hospital of Guangzhou Medical University, Guangzhou, China; ${ }^{3}$ Department of VIP Region, Sun Yat-Sen University Cancer Center, Guangzhou, \\ China; ${ }^{4}$ Department of Respiratory Medicine, The Sixth Affiliated Hospital of Guangzhou Medical University, Qingyuan, China; ${ }^{5}$ Department of \\ Respiratory Medicine, The First Affiliated Hospital of Guangzhou Medical University, Guangzhou, China; ${ }^{6}$ The First People Hospital of Zhaoqing, \\ Zhaoqing, China \\ Contributions: (I) Conception and design: W Liang, J He; (II) Administrative support: W Liang, J He; (III) Provision of study materials or patients: \\ M He, Q He, W Liang, J He; (IV) Collection and assembly of data: M He, Q He, X Cai; (V) Data analysis and interpretation: All authors; (VI) \\ Manuscript writing: All authors; (VII) Final approval of manuscript: All authors. \\ \#These authors contributed equally to this work. \\ Correspondence to: Wenhua Liang, Jianxing He. Department of Thoracic Surgery and Oncology, the First Affiliated Hospital of Guangzhou Medical \\ University; Guangzhou Institute of Respiratory Disease \& China State Key Laboratory of Respiratory Disease, No. 151, Yanjiang Rd, Guangzhou \\ 510120, China. Email: liangwh@gird.cn; drjianxing.he@gmail.com.
}

Background: As lymphatic vessel is a major route for solid tumor metastasis, they are considered an essential part of tumor drainage conduits. Apart from forming the walls of lymphatic vessels, lymphatic endothelial cells (LECs) have been found to play multiple other roles in the tumor microenvironment, calling for a more in-depth review. We hope that this review may help researchers gain a detailed understanding of this fast-developing field and shed some light upon future research.

Methods: To achieve an informative review of recent advance, we carefully searched the Medline database for English literature that are openly published from the January 1995 to December 2020 and covered the topic of LEC or lymphangiogenesis in tumor progression and therapies. Two different authors independently examined the literature abstracts to exclude possible unqualified ones, and 310 papers with full texts were finally retrieved.

Results: In this paper, we discussed the structural and molecular basis of tumor-associated LECs, together with their roles in tumor metastasis and drug therapy. We then focused on their impacts on tumor cells, tumor stroma, and anti-tumor immunity, and the molecular and cellular mechanisms involved. Special emphasis on lung cancer and possible therapeutic targets based on LECs were also discussed.

Conclusions: LECs can play a much more complex role than simply forming conduits for tumor cell dissemination. Therapies targeting tumor-associated lymphatics for lung cancer and other tumors are promising, but more research is needed to clarify the mechanisms involved.

Keywords: Lymphatic endothelial cell (LEC); tumor; microenvironment

Submitted Jan 18, 2021. Accepted for publication Mar 19, 2021.

doi: $10.21037 /$ tlcr-21-40

View this article at: http://dx.doi.org/10.21037/tlcr-21-40 


\section{Introduction}

Though most solid tumors disseminate through lymphatic vessels before hematogenous metastasis (1), the lymphatic system is relatively overlooked compared to the tumor microenvironment blood vessels. Traditionally, the lymphatic vasculature has been considered a draining route for interstitial fluid and migrating leukocytes and tumor cells. The lymphatic endothelial cell (LEC) is the primary cell that builds lymphatic vasculature, forming the wall of lymphatic vessels which transport the fluid and migrating cells inside (2). In the tumor lymphatic metastasis, invaded malignant cells need to squeeze between LEC junctions and move along LECs towards lymph nodes (LNs) and distant organs. Thus, LECs are an essential part of the tumor micro-environment, facilitating cancer invasion and may be harnessed by tumor cells (3). Indeed, LEC infiltration and lymphatic vessel formation are observed frequently in a highly active tumor, and this process is called tumorassociated lymphangiogenesis (4). Recent advances also revealed that, besides this bystander role, LECs could function in multiple other ways during tumor progression, tumor-stimulating or inhibiting, and interaction with tumor cells, immune cells, or tumor stroma (5-7). These interactions can also occur in both peripheral lymphatics and the tumor-draining lymph nodes (TDLNs) (8), implying the existence of distinct populations of LECs and the context-dependent interaction. In this sense, LECs' complex roles in the tumor micro-environment and recent advances in this field call for an in-depth inspection.

In this review, we aimed to summarize recent advances in the study of LECs in the tumor microenvironment, focusing on their roles in cancer progression and interaction with different cell populations, together with the underlying molecular mechanisms. This review may help researchers better understand the field and shed some light upon further research directions. We thus hope that the lymphatic system, especially LECs, should gain more attention in cancer researchers, and effective therapies targeting LECs can be developed in the recent future.

To achieve an informative summary of recent research advances, we did a careful search of Medline database for English literature that covered the topic of LEC or lymphangiogenesis in cancer progression or therapies openly published from the January 1995 to December 2020. Two different authors carefully examined the literature abstracts to exclude possible unqualified ones, and 310 papers with full texts were finally retrieved. We present the following article in accordance with the Narrative Review reporting checklist (available at http://dx.doi.org/10.21037/ tlcr-21-40).

\section{Structure of lymphatic vessels}

Lymphatic microvessels start as a blind end in peripheral tissue, consisting of a single layer of LECs and minimal basement membrane. They are not covered by smooth muscles or pericytes that may be found in larger collecting lymphatic vessels. Also, junctions between the capillary LECs are discontinuous, and gaps on the microvessel wall are frequently found. These together can facilitate uptake of fluid, molecules, and migrating cells from peripheral tissues. As the capillary lymphatics converge into collecting lymphatics, the gaps between LECs will be replaced by the continuous junction.

Moreover, smooth muscles surround the collecting lymphatic vessel wall to increase its flexibility. These collecting vessels will then meet on larger afferent lymphatic vessels opening into the draining lymph nodes (LNs). To better prevent reversing of lymphatic flow, LEC-covered bi-leaflet valves are also present, mainly in collecting lymphatics or places where afferent vessels meet the LNs (9). In this way, lymphatic vessels form the draining system from the periphery towards LNs. Thus, the above is the classic view of the lymphatic structure in the tumor micro-environment, forming the conduit for tumor cell metastasis. LECs are the actual bricks that build this complex structure. Consistent with this notion, the presence of tumor lymphangiogenesis is correlated with a higher frequency of LN and distant metastasis, observed in several types of human cancers, including lung cancer (10), melanoma (11), colorectal cancer (12) and breast cancer (13). Through the staining of key markers, LECs is shown to be an integral part of them in the tumor micro-environment. However, there is still a discrepancy on whether lymphatic microvessel density (LMVD) in the center of or around the tumor is of better prognostic value for metastasis (14-18). Though penetrating LECs may have better contact with tumor cells, LECs surrounding tumor mass with a less compact environment may function better for tumor cell drainage. Thus, defining the functioning LECs may be a better approach, but this needs a more in-depth digging into the phenotype change of LECs under different circumstances. 
In recent years, the lymphatic structure in TDLNs has also gained more attention. Within the LN, the afferent lymphatics transform into subcapsular sinus systems. The subcapsular sinus usually overlays the whole LN cortex, and is lined by LEC layers on both sides. Those facing the capsule are called ceiling LECs, and those overlaying the parenchyma are called floor LECs (19). The subcapsular sinus is hence the first place in TDLNs met by tumor cells and leukocytes. Apart from migrating tumor cells and leukocytes, subcapsular sinus is also dwelled by resident immune cells, such as resident macrophages and dendritic cells (DCs) $(20,21)$, which are usually interspersed with floor LECs. The migratory, as well as resident leukocytes, need to transverse floor LECs to initiate immune response of effector cells in the subcapsular niche. Recent evidence also showed that LEC-produced growth factors and chemokines are essential for the development of subcapsular macrophages $(22,23)$. On the hilum side of LNs, the subcapsular sinus is replaced by the medullary sinus, which will finally converge into the efferent lymphatic vessels for drainage away from LN. In this sense, efferent leukocytes need to travel across the LECs at the boundary. Tumor cells also need to infiltrate LN parenchyma across floor LECs, however, their choice of exiting routes from $\mathrm{LN}$ are still unclear (24). Besides subcapsular and medullary sinuses, two other types of sinuses exist, namely the transverse and cortical sinuses, which will merge into the medullary sinuses. The transverse sinuses are invaginations of the subcapsular sinus (25), and cortical sinuses are blind-ended sacs in the paracortical zone (26). However, their exact roles in tumor metastasis are still not fully defined.

Interestingly, the structure of lymphatic vessels can be remodeled during tumorigenesis (2). For example, to facilitate tumor cell entry, junctions between tumor-associated LECs are loosened to allow better permeability (27). Lymphatic vessel remodeling may be due to the interaction with tumor stroma. The expression of sub-endothelial matrix protein, such as collagen, fibrillin, and biglycan, is reduced, leading to a lack of structural support and increased inter-LEC gaps (28). Moreover, in collecting lymphatics, lymphatic caliber can be enlarged, and surrounding smooth muscle contraction can be blocked by signals from migrating tumor cells $(14,29,30)$, including lymphangiogenic factors vascular endothelial growth factor C/D (VEGF-C/D) and the downstream vasodilators, such as prostaglandin (31). This vessel enlargement can then contribute to a less compact environment for the survival of tumor cells and an increased flow of lymph fluid for their dissemination.

\section{Sequential steps of tumor lymphatic metastasis}

While the classical view of lymphatic metastasis is a passive transport of tumor cells under lymphatic fluid pressure, it is now confirmed that lymphatic metastasis is more likely the result of a mutual interaction between tumor cells and tumor microenvironment, such as the LECs. Theoretically, sequential steps should be followed during tumor lymphatic metastasis, from a primary tumor site to the invaded LNs and distant organs (Figure 1). Firstly, malignant cells need to enter the peripheral lymphatic microvessel at primary tumor sites. Contact between tumor cells and peripheral LECs may be achieved by direct invasion due to tumor proliferation or tumor-induced lymphangiogenesis into and around tumor mass. Secondly, invaded tumor cells migrate within lymphatic vessels towards LNs. Key questions on this step involve the force that drives the unidirectional flow of tumor cells. Thirdly, tumor cells reside and grow in the metastatic LNs (32). Migrating into LN parenchyma and overcoming the anti-tumor immunity is essential for tumor cells' survival within LNs. With the thoracic duct connecting lymphatic and blood vessels, tumor cells then spread to systematic circulation and colonize distant organs. Recent evidence from murine models also showed that tumor cells may also spread through blood vessels of LNs rather than by efferent lymphatics $(24,33)$. This mode suggested that tumor cells in invaded LNs can disseminate to distant organs without the need of drainage into thoracic ducts. However, whether this form of tumor dissemination beyond LNs occur in human patients still needs to be determined (34).

Thus, tumor-associated lymphangiogenesis and lymphatic vessel remodeling may aid in multiple tumor metastasis aspects (2). Lymphatic vessel structure, the interaction between LECs and other cell populations, together with the underlying mechanisms, is of special significance for understanding and managing tumor lymphatic metastasis. These will be discussed in more details below.

\section{Differentiation and markers of LECs}

\section{Differentiation of LECs}

While LECs share the same endothelial precursor cells with blood endothelial cells (BECs), the transcriptional factor Prox-1 (Prospero homeobox protein 1) determines the specification of LEC fate from BECs and expression of key LEC marker, such as vascular endothelial growth factor 


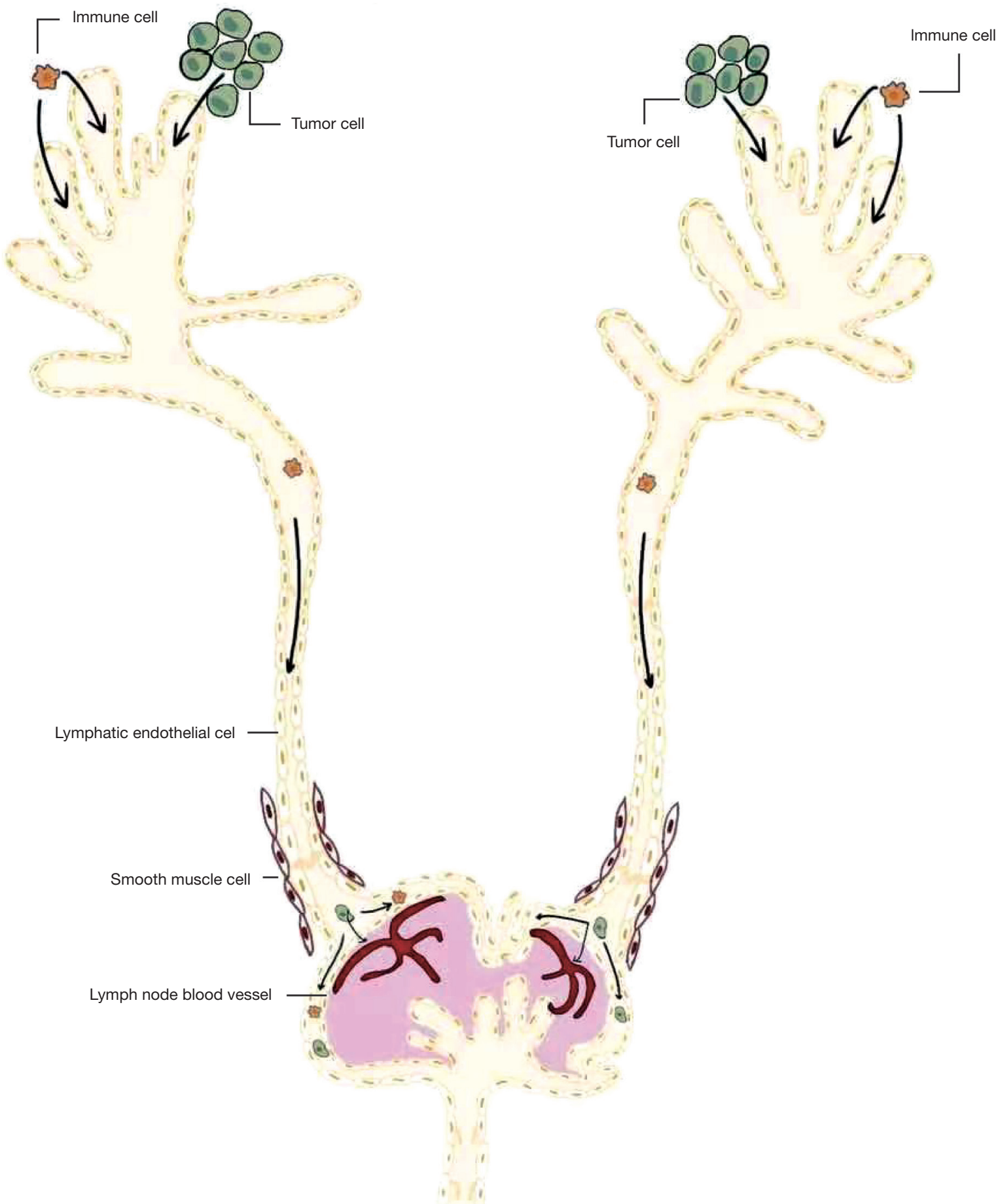

Figure 1 Sequential steps of tumor lymphatic metastasis. Sequential steps are followed during tumor lymphatic metastasis, from a primary tumor site to collecting lymphatic vessel and the draining lymph nodes. They can also invade lymph node blood vessels to colonize distant organs. 
receptor-3 (VEGFR-3) $(35,36)$. Latter findings also proved that Sox18 [SRY (sex-determining region Y) box 18], which binds to the promoter region of Prox-1, can induce its expression and then LEC differentiation from the cardinal vein (37). Moreover, the Ets-2 transcriptional factor can act as a co-factor of Prox-1 to enhance VEGFR-3 expression. The above changes can also lead to increased lymphangiogenesis (38). Consistent with these findings, factors that downregulate Prox1 can result in dedifferentiation from LECs to BECs (39). The above again emphasizes the central role of Prox-1 in determining LEC differentiation and lymphangiogenesis.

Apart from the lineage generation from BECs, structural modeling, such as sprouting, marks another feature during differentiation of LECs. Similar to its effect on BECs, Notch signaling inhibition can work to induce LEC sprouting. LECs transduced with its ligand, the delta-like ligand 4 (Dl14), preferentially adopted a tip cell position. In this sense, the Notch signaling can determine the tip-stalk specification in LECs' growing sprouts (40).

In recent years, evidence showed that generation of lymphatic endothelial lineage in adult organisms, such as tumor lymphangiogenesis, may more likely take on a myloid origin (41). This population of myloid lymphatic endothelial cell progenitors (M-LECP) derive from bone marrow hematopoietic progenitor cells that can co-express myloid and LEC markers (42). During tumorigenesis, M-LECPs can differentiate in bone marrow and be recruited from blood circulation to be integrated into tumor-associated lymphatic vessels. From murine model of human cancer, it was also shown that the density of M-LECPs can be associated with LN metastasis (43).

\section{Markers of LECs}

With pan-endothelial markers, such as CD31 and VCAM, expressed on BEC and LEC, researchers have been trying to find marker genes to distinguish them, as LECs show distinct phenotypes and functions. Being a master regulator of differentiation for LEC, Prox- 1 is deemed a key LEC marker (36), together with VEGFR-3, which forms the receptor for lymphangiogenic VEGF-C/D (44). However, to efficiently identify lymphatic vessels in the tumor micro-environment, another two markers were more generally used in research and clinics, namely lymphatic vessel endothelial hyaluronic acid receptor 1 (LYVE1) and podoplanin (45-47). Podoplanin, detected with the commercially available monoclonal antibody D2-40, is expressed on all LEC types, but LYVE1 is found only on small peripheral vessels while missed on collecting lymphatic vessels. Indeed, staining of D2-40 shows a significant correlation with tumor lymphangiogenesis and a worse prognosis of cancer (48).

Moreover, besides the general LEC markers mentioned above, LECs in different LN sinuses may express distinct molecules concerning the sinus systems' specialized functions. Indeed, recent advances in singlecell sequence analysis offered great help (49). It revealed that CD73 and caveolin 1 are expressed in ceiling LECs of subcapsular sinus, and tumor necrosis factor receptor superfamily member 9 (TNFRSF9) is found in the floor LECs. While macrophage receptor with collagenous structure (MARCO) is expressed in both medullary and cortical sinuses, microfibril-associated glycoprotein 4 (MFAP4) was mainly found on LECs of the capsule ceiling of the medulla and claudin 11 on LECs of lymphatic valves (49).

With these identifiers, researchers are better equipped to study LECs in the tumor micro-environment. Immunostaining of LEC markers can help identify them in tissue slides. Cell sorting based on specific LEC markers can acquire relatively pure LEC populations, which may be used later for in vitro and in vivo experiments. While some molecules have clear functions, such as VEGFR-3, which is the receptor for lymphangiogenic factor VEGF-C/D, we still do not know much about the rest's functions.

\section{Molecular mechanism of tumor lymphangiogenesis}

\section{Vascular endothelial growth factors}

As increased lymphangiogenesis is correlated with a higher rate of tumor metastasis $(50,51)$, it is no wonder various lymphangiogenic growth factors can be found in the tumor micro-environment to facilitate LEC proliferation and morphological change (Figure 2). The most potent stimulating factor for LEC growth has been proved to be VEGF-C, which is correlated with lymphangiogenesis, LN metastasis, and worse prognosis of a tumor, demonstrated by supplementing or blocking VEGF-C in murine models of human cancer $(14,15)$. VEGF-C, together with the relatively less potent ligand VEGF-D $(31,52)$, binds to the receptor tyrosine kinase VEGFR-3, which will later induce a protein kinase $\mathrm{C}$ (PKC) - dependent activation of $\mathrm{p} 42$ / 


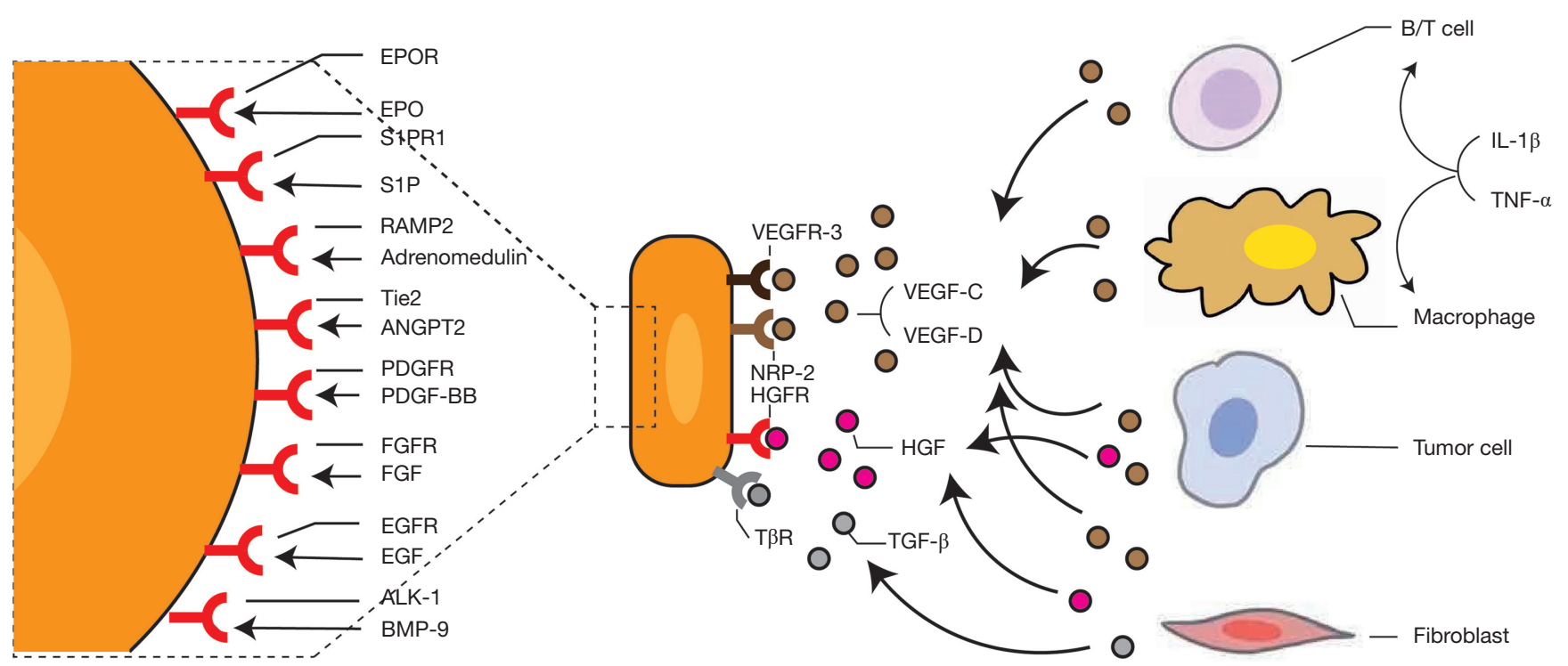

Figure 2 Lymphangiogenic and anti-lymphangiogenic factors in tumor-environment. Molecules that may influence lymphangiogenesis are shown, with their corresponding receptors. For a better view of the receptors, a magnification of LEC is shown on the left. LEC, lymphatic endothelial cell; VEGF, vascular endothelial growth factor; VEGFR ,VEGF receptor; TNF- $\alpha$, tumor necrosis factor; EPO, erythropoietin; EPOR, EPO receptor; S1P, Sphingosine-1-phosphate; S1PR1,Sphingosine 1-phosphate type 1 receptor; RAMP2, receptor activity modifying protein 2; ANGPT, angiopoietins; Tie2, ANGPT receptor; PDGF, platelet-derived growth factor; PDGFR, PDGF receptor; FGF, fibroblast growth factor; FGFR, FGF receptor; EGF, epidermal growth factor; EGFR, EGF receptor; HGF, hepatocyte growth factor; HGFR, HFG receptor; TGF- $\beta$, transforming growth factor $\beta$; T $\beta$ R, TGF- $\beta$ receptor; NRP-2, neuropilin-2; BMP-9, bone morphogenetic protein 9; ALK-1, activin receptor-like kinase 1.

p44 MAPK and Akt phosphorylation (31). The downstream signaling then leads to increased survival, growth, and migratory ability of LECs. Consistent with this, VEGF-Cinduced lymphangiogenesis and tumor progression can be completely inhibited by blocking VEGFR-3, emphasizing the central role of the VEGF-C/D-VEGFR-3 axis for LEC growth (53).

In addition to the VEGF-C/D-VEGFR-3 axis, molecules that regulate them can also play a role in tumor lymphangiogenesis. For instance, WNT1, which can suppress VEGF-C expression, leads to reduced lymphangiogenesis and delayed LN metastasis in the mouse model of melanoma (54). On the other hand, cyclooxygenase 2 (COX2), which can synthesize prostaglandins to promote VEGF-C production, can increase tumor-associated lymphangiogenesis and $\mathrm{LN}$ metastasis $(55,56)$. Interestingly, the VEGF-D-induced collecting vessel dilation may be through the regulation of PGDH, which will lead to increased production of prostaglandins (29). Similarly, collagen and calcium-binding EGF domain-1 (CCBE-1) can enhance VEGF-C proteolysis to promote its maturation and tumor lymphangiogenesis (57). Moreover, neuropilin-2 (NRP-2), which functions as a co-receptor of VEGFR-3 or as an independent receptor of VEGF-C/D, can work in synergy with them to further induce LEC growth, migration, reconstruction, and tumor lymphangiogenesis $(58,59)$, even though NRP-2 itself can also induce cancer cell extravasation and metastasis (60). Thus, modulation of the lymphangiogenic VEGF-C/D-VEGFR-3 pathway offers another layer of molecular regulation for tumor lymphangiogenesis.

In addition to tumor cell-derived lymphangiogenic factors, recruited myloid cells can be an important source of VEGF-C (61). Circulating monocytes are recruited by tumor-derived chemotactic factors, and can be switched to alternatively activated macrophages in TME (62). Being a key component of infiltrating myloid in tumor tissues, tumor-associated macrophages (TAMs) is shown to be involved in the onset and maintenance of tumor lymphangiogenesis. They can express large amount of VEGF-C/D, which may be triggered by cytokines, such as IL-1 $\beta(63,64)$. 


\section{Otber lymphangiogenic growth factors}

Apart from VEGF-C/D, other lymphangiogenic growth factors have also been found, including fibroblast growth factor (FGF) $(65,66)$, epidermal growth factor (EGF) (67), hepatocyte growth factor (HGF) (68), platelet-derived growth factor (PDGF) (32), angiopoietins (ANGPTs) (27), adrenomedullin (AM) $(69,70)$, Sphingosine-1-phosphate (S1P) (71), and erythropoietin(EPO) (72) (Figure 2). For example, collaboratively with VEGF-C, FGF-2 can act through FGFR-1 on LECs to stimulate lymphangiogenesis. Nevertheless, this effect is only found in lymphatic tip cells induced by VEGFR-3 activation (66). Similarly, EGF correlates with VEGF-C and Prox-1 expression in human primary melanoma, and tumor-derived EGF works synergistically with VEGF-C to promote LEC sprouting (67). Moreover, HGF from fibroblasts can exert its lymphangiogenic effect in cooperation with the VEGF-C by activating the Erk 1/2 signaling or independently activating the hepatocyte growth factor receptor (HGFR)/ c-MET pathway $(73,74)$. Much in an independent way from VEGF-C/D, PDGF-BB from fibrosarcoma cells can induce tumor lymphangiogenesis and enhance metastasis in LNs. Its stimulation of PDGFR leads to increased levels of phosphorylated Src (P-Src), Erk 1/2 (P-Erk1/2), and Akt (protein kinase B), making it a survival factor for newlyformed LECs (32).

Using mouse models of pancreatic $\beta$-cell carcinoma, researchers proved that ANGPT-1- and ANGPT-2expressing $\beta$-cell tumors showed increased peritumoral lymphangiogenesis (75). Also, ANGPT-2 antibody, which blocks its interaction with the endothelial TEK (Tie2) tyrosine kinase receptor, can attenuate lymphangiogenesis and reduce tumor cell dissemination via lymphatic vessels (27). This effect of the ANGPT-2 antibody is possibly through restoring the integrity of endothelial cellcell junctions reduced by ANGPT-2 effects. As with the case of AM, it increases lymphatic vessel density (LVD) at tumor margin and the draining LNs $(69,76)$. It is through its acting on calcitonin receptor-like receptor (CLR) and the associated receptor activity modifying protein 2 (RAMP2), which will lead to increased Erk1/2 activation and LEC proliferation (70). Similarly, S1P generated by sphingosine kinase 1 (SphK1) induces lymphangiogenesis around the primary tumor and in the TDLNs (71). It may be through the $\mathrm{S} 1 \mathrm{P} 1$ receptor, which can later activate the downstream $\mathrm{G}_{\mathrm{i}} / \mathrm{PLC} / \mathrm{Ca}^{2}$ signaling pathways (77).
Moreover, EPO, which is often raised due to anemia caused by cancer therapy, increases migration, capillarylike tube formation, and dose and time-dependent LEC proliferation. This is possibly through directly activating the PI3K/Akt and ERK1/2-dependent pathways in LECs or increasing VEGF-C expression in $\mathrm{CD}_{1} 1 \mathrm{~b}^{+}$macrophages from LNs and bone marrow-derived macrophages. However, it is interesting that, this EPO-induced tumor lymphangiogenesis seems to mainly occur in TDLNs rather than in peripheral lymphatics (72).

\section{Inflammation}

It has long been known that lymphangiogenesis will be induced under inflammation, possibly for the drainage and resolution of an excessive inflammatory response. It is through inflammatory cytokines that can induce lymphangiogenic factors $(78,79)$ (Figure 2). Results showing the correlation between inflammation and carcinogenesis poses the question of whether inflammation-induced lymphangiogenesis may also be an underlying mechanism. IL-1 $\beta$ can promote tumor lymphangiogenesis and LN metastasis through recruitment of M2-type macrophage (63). It is consistent with evidence that IL-1 $\beta$-induced lymphangiogenesis depends on the recruitment of leukocytes (80). Other inflammatory factors, such as tumor necrosis factor (TNF- $\alpha$ ), show lymphangiogenic effect in a similar way meditated by the infiltrated inflammatory cells $(64,81,82)$, emphasizing their role in attracting VEGF-C-producing leukocytes. Moreover, the anti-inflammatory cytokines IL10 can upregulate VEGF-C expression from macrophage, resulting in increased lymphangiogenesis and resolution of inflammation (83). Apart from their role in recruiting migrating leukocytes, the inflammatory factors can also regulate tumor cells to potentiate lymphangiogenesis. Indeed, IL-1 $\beta$ from tumor-associated-macrophages (TAMs) can stimulate LECs' proliferation and migration directly (84). Also, IL-6, a potent inflammatory cytokine, can induce VEGF-C production in oral squamous cell carcinoma (OSCC) and increase OSCC-related lymphangiogenesis (85). Interestingly, research also showed that active lymphangiogenesis presents more in inflammatory breast cancer than in non-inflammatory breast cancers $(86,87)$. Thus, this finding may be additional evidence for the association between inflammation and tumor-associated lymphangiogenesis and then worse prognosis of cancer. 


\section{Extracellular matrix (ECM)}

It has long been recognized that interaction with the ECM plays an important role in tumor lymphangiogenesis (88). On the one hand, ECM proteins, such as collagens (89), laminins (90), and fibronectins (91), can provide the essential structural support for LECs. Indeed, integrins expressed on LECs, which facilitate adhesion to the ECM protein fibronectin, are necessary for LEC anchorage and tumor lymphangiogenesis (92). Adhesion to ECM through integrin can lead to phosphorylation of VEGFR-3 (93). Thus, integrin is required for LEC migration and invasive response to lymphangiogenic factors together with its downstream signaling pathways. In line with this, and CD9 also shows supporting function for LECs that may involve modulating the molecule organization of integrin (94). The depletion of CD9 impairs the interplay between integrin and VEGFR-3, resulting in diminished VEGFR-3 signaling in LECs and tumor-associated lymphangiogenesis. On the other hand, remodeling of ECM, possibly by matrix metalloproteinase (MMP) that can and provide a looser environment, can help greatly for lymphangiogenesis (95). Serving as an efficient collagenase, MMP-2 strongly drives the LEC migration through the collagen matrix. However, it should also be noted that MPPs are not always lymphangiogenic, as the membrane type 1-MMP (MT1MMP) is found to degrade LYVE-1 on LECs, which then leads to inhibition of LYVE-1-mediated lymphangiogenic responses (96).

\section{Factors downregulating tumor lymphangiogenesis}

While many lymphangiogenic factors have been identified, there also exist some anti-lymphangiogenic factors (Figure 2). For instance, transforming growth factor- $\beta$ (TGF- $\beta$ ) transduced signals in LECs and negatively regulated their proliferation, migration, and cord formation. Expression of LEC markers, including LYVE-1 and Prox -1 , was repressed by TGF- $\beta$ but can be induced by TGF- $\beta$ type I receptor (T $\beta R-I)$ inhibitor in pancreatic adenocarcinoma xenograft models of mice (97). Moreover, bone morphogenetic protein 9 (BMP-9), another member of the TGF- $\beta$ superfamily, can act on its receptor activin receptor-like kinase 1 (ALK-1) to downregulate Prox-1 expression and cyclin family members, such as CCNE2. This leads to reprogramming of BEC to LEC and reduced tumor lymphangiogenesis in a mouse model of breast cancer (39). Thus, the lymphangiogenic and anti-lymphangiogenic factors may cooperate to determine LEC fate and proliferation. When this balance is lost, pathological conditions, such as cancer, may occur afterwards (98).

\section{Role of lymphangiogenesis in cancer progression}

\section{Role of lymphangiogenesis in tumor metastasis}

As was discussed above, the lymph vessels can serve as conduits for promoting tumor cell metastasis $(99,100)$. Besides this, multiple other functions are found (Figure 3). On the one hand, LECs can express chemotactic factors for tumor cell mobilization within lymphatic vessels. On the other hand, they are also likely to modulate anti-tumor immunity in the periphery or TDLNs. The association between lymphangiogenesis and tumor metastasis is shown for NSCLC and melanoma, in which the incidence of intratumoural and peritumoral lymphatics is correlated with LN invasion and poor overall survival $(10,101)$.

As the number and density of LECs in and around tumor mass increase, contact opportunities between them and tumor cells are bound to be raised. Concerning the compaction in tumor mass, lymphatic vessels provide a relative comfortable environment for tumor cells. They are also under much smaller hydrodynamic stress in the lymphatic vessels compared with the circulating system, thus are of better survival rate during lymphatic metastasis. Moreover, higher numbers of functional lymphatics can result in better drainage of lymphatic fluid and lower interstitial pressure, which will lead to increased blood perfusion and nutrition supplements for tumor cells (53). It is interesting that LECs might stimulate a distinct population of cancer stem cells (CSCs) through the CXCL12/CXCR4 axis, highlighting their role as niche and protector for the metastatic tumor cells (102).

As was mentioned above, migration along LECs with lymphatics is also an essential part of tumor lymphatic metastasis. However, the question is to identify the driving force for this flow of metastatic tumor cells. LECs facilitate this step by providing chemokines that can attract tumor cells expressing the respective receptors, such as CCR7 and CXCR4 (103). The chemokine gradient towards TDLNs is generated by the flow of interstitial fluid, guaranteeing the unidirectional migration of tumor cells along lymphatic vessels and into TDLNs (104). Interestingly, LECs may utilize distinct mechanisms for attracting tumor cells along collecting lymphatic vessels or into the sinus system of the LN (105). Together, this evidence emphasizes 


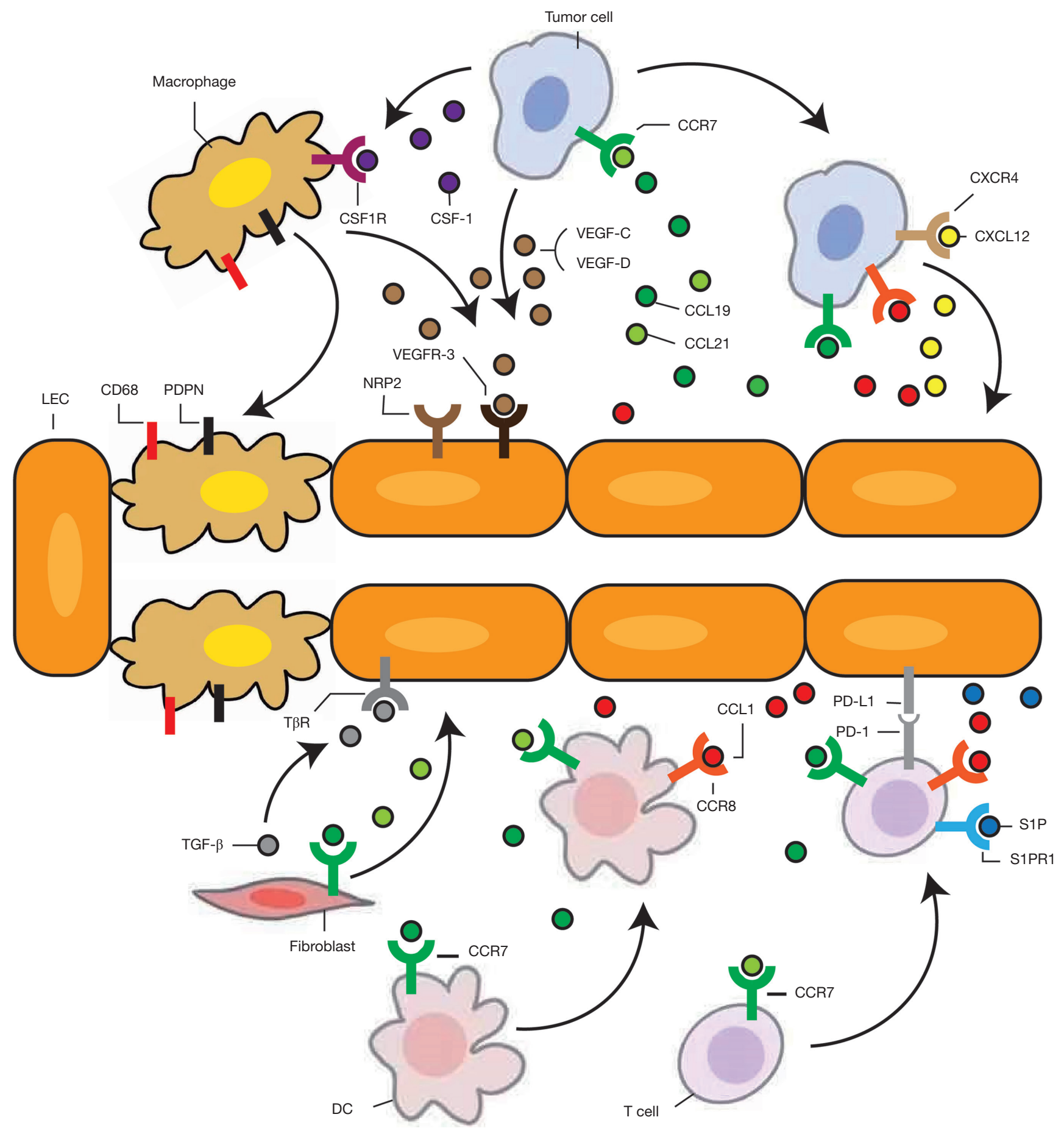

Figure 3 Interaction between lymphatic endothelial cells and tumor micro-environment. LECs can secret chemokines to recruit tumor cells, immune cells and fibroblasts. They can also affect tumor cell survival and immune cell function. Macrophages can be recruited and integrated into lymphatic vessels. CCL1, CC-chemokine ligand 1; CCL19, CC-chemokine ligand 19; CCL21, CC-chemokine ligand 21; CXCL12, CX-chemokine ligand 12; CCR7, CC-chemokine receptor 7; CCR8, CC-chemokine receptor 8;CXCR4, CXC-chemokine receptor 4; VEGF, vascular endothelial growth factor; VEGFR, VEGF receptor; NRP-2, neuropilin-2; TGF- $\beta$, transforming growth factor $\beta$; T $\beta R$, TGF- $\beta$ receptor; S1P, Sphingosine-1-phosphate;S1PR1,Sphingosine 1-phosphate type 1 receptor; PD-1, programmed cell death-1; PD-L1, PD-1 ligand 1; DC, Dendritic cells; PDPN, podoplanin. CSF-1, colony-stimulating factor 1; CSF1R, CSF-1 receptor. 
the checkpoint role of LECs producing chemokines for powering tumor cell migration.

The role of LECs in modulating anti-tumor immunity has just come to notice in recent years. On the one hand, LEC-produced chemotaxis signals are essential for antigenloading DCs homing LNs (106), as well as effector immune cells infiltrating primary tumor sites $(107,108)$. These suggest that effective modulation of tumor immunity requires LEC participation. On the other hand, LECs in tissue lymphatics and LNs share some common features with professional antigen-presenting cells (APCs). They may induce self-tolerance through scavenging and crosspresenting tumor antigens to downregulate anti-tumor immunity $(109,110)$.

\section{Role of lymphangiogenesis in cancer therapy}

Compared with blood vessels, solid tumors may prefer to disseminate through the lymphatics, as the lymphatic vasculature has wider vessel lumens, decreased fluid pressure, and increased endothelial permeability $(111,112)$. In this sense, during the treatment of tumor cells, the production of pro-lymphangiogenesis factors aforementioned are likely to accumulate. For example, as an alternative pathway for tumor survival and chemotherapy treatment resistance, VEGF-C expression by tumor cells can be found to be significantly increased under antitumor chemotherapies, such as docetaxel, vinorelbine (113). Specifically, docetaxel treatment of breast cancer caused an upregulation in pro-lymphangiogenic factors, including VEGF-C and TNF- $\alpha$ in the tumor microenvironment (114). Moreover, structural remodeling of LECs was also seen during the treatment of paclitaxel, in which LEC autophagy was increased, and higher permeability of lymphatic endothelium was induced to allow malignant progression and metastatic lesions (115).

Currently, most antineoplastic drugs are administered systematically, such as intravenously or via the oral route. However, evidence showed that they could hardly reach an efficient anti-tumor concentration in lymphatic vessels $(92,93)$, making it hard to kill the tumor cells in lymphatic transit or in metastasized LNs. This makes lymphatic vessels an important shield for cancer cells from anti-tumor drugs (116). To overcome these problems, modification of the drug administrating route, such as modification of the drug administrating route has been developed. The novel lymphatic targeting delivering systems include liposomes to target the lymphatics by subcutaneous administration, epirubicin-loaded polymeric micelles to effectively treat axillary LNs metastasis of breast cancer through selective accumulation and $\mathrm{pH}$-triggered drug release, MPEG-DSPE polymeric micelle for translymphatic chemotherapy of LN metastasis and engineering polymer hydrogel nanoparticles for LN-targeted delivery. But their efficacy in clinical practice needs to be determined in future studies (117-120).

Even though the above evidence mainly pointed to a resistance-promoting role of tumor-associated LECs, it was also found that tumor lymphangiogenesis can be associated with a better response to immunotherapy of melanoma (121). The detailed mechanistic study revealed that chemokines produced by capillary LECs, such as CCchemokine ligand 21 (CCL21) that acts on CCR7, can induce the infiltration of naive but not effector $\mathrm{T}$ cell. These naive $T$ cells will then be locally activated, leading to the upregulation of cytotoxic $\mathrm{T}$ cells in the tumor microenvironment (121). This may imply that, while LECs facilitate the recruitment of immune cells, the local tumor micro-environment educates them to be either immunogenic or tolerant. Tumor lymphangiogenesis should be reduced to increase the efficacy of certain types of cancer therapies, but may also need to be reserved for others.

\section{Interaction between lymphatic endothelial cells with tumor microenvironment}

\section{Interaction between lymphatic endothelial cells and tumor cells}

Like tumor cells, by their nature, seek infinite proliferation, the growth pressure selects those that can take the best advantage of the tumor micro-environment, including LECs, for their growth and survival. Evidence has indeed shown that tumor cells are an important source of lymphangiogenic VEGF-C/D (14,52). In animal models of human cancers, tumor cells expressing a high level of other lymphangiogenic factors, such as ANGPT2, FGF-2, and PDGF-BB, are found with increased tumorassociated lymphangiogenesis and lymphatic metastasis $(27,32,66)$. Acting on their respective receptors, these factors from tumor cells provide the essential signals for LEC proliferation, migration, and tube formation. More evidence was recently revealed on the role of chemokinechemokine receptor interaction for tumor-associated lymphangiogenesis, especially tumor-induced LEC migration. For instance, tumor-derived CCL27/28 can 
act on the CCR10 receptor on LECs to promote their recruitment (122).

Besides the induction of lymphangiogenesis in the periphery, LEC proliferation and lymphatic remodeling were also observed beyond the primary tumor site. These changes include the enlargement of collecting lymphatics and increased lymphatic density in TDLNs $(123,124)$. Tumor-associated lymphangiogenesis can be through secretion of the classical VEGF-C (124) or other tumorderived particles, such as extracellular vesicles (125), which may contain and can be taken in by adjacent or distant LECs $(126,127)$. Interestingly, this change beyond primary tumor sites can actually occur before the actual arrival of metastatic tumor cells $(124,128)$, forming the premetastatic niche (PMN) that can encourage the growth of the incoming tumor cells (129). This again implied that lymphangiogenesis takes an active role in promoting tumor metastasis while not a concomitant change with cancer progression.

Recent advances in their interaction revealed that LECs are also able to provide migrating signals for tumor cells (Figure 3). Tumor cells can express CCR7, which can work as receptors for LEC-produced chemokine CCchemokine ligand 19 (CCL19) and CCL21 and function together for tumor cell chemotaxis $(130,131)$. In mouse xenografts of melanoma cell lines expressing CCR7, tumor cells grew directionally towards the LEC depot (131). In line with this, the expression of CCR7 is associated with increased LN metastasis of gastric carcinoma. It is interesting that the lymphangiogenic VEGF-C can also induce CCL2 1 production from LECs, emphasizing its role in the chemokine-chemokine receptor interplay for tumor lymphatic metastasis (132). As tumor cells migrate towards LNs, another pair of the chemokine-chemokine receptor, namely the CC-chemokine ligand 1 (CCL1)CCR8 axis, will come into play (105). Since CCL1 is found just in LN but not peripheral LECs, acting on the CCR8 on the tumor cell surface, it may work mainly to control the entry of tumor cells into LNs (105). Blocking CCR8 leads to the arrest of tumor cells in collecting lymphatics at junctions where they meet subcapsular sinuses, resulting in significantly decreased LN metastasis. Interestingly, this research also revealed that CCL1 production in LECs is stimulated by inflammatory factors, such as TNF, IL-1 $\beta$, and LPS. This implies that local inflammation may boost the invasion of tumor cells towards LN (105).

Similar interactions between LECs and tumor cells were also found with the CXCL9/CXCL10/CCL21-
CXCR3 and CXCL12-CXCR4 axes $(103,133,134)$, showing that $\mathrm{CXCR} 3^{+}$and $\mathrm{CXCR} 4^{+}$cancer cells are bound with an increased propensity of LN metastasis. Moreover, concerning the association between the CXCR4 receptor and the stemness of cells, the action of LEC-produced CXCL12 through CXCR4 can induce a small population of melanoma cells with elevated expression of CD133, which acquire a CSC phenotype and show stronger resistance to chemotherapy (102). Similarly, CCR7 can induce the functional pool of stem-like cells in breast cancer cells (135), though whether or not LEC-derived CCL19 and CCL21 plays a role in this change still needs to be determined. Also, CXCL5 from LECs can promote tumor cell invasion by acting on CXCR2 (5). Moreover, LECs may secret mitogenic factors, such as IL-6, to directly boost the proliferation of tumor cells (136). Taken together, by the promotion of tumor cells with stronger viability, such as the CSC population, LECs may serve to provide a cultivating environment for the highly invasive cancer cells (111). However, it should also be cautious as whether these factors have sufficient influence on the collective behavior of tumor mass, and more research is needed to elucidate the role of LECs in directly promoting tumor cell growth.

\section{Interaction between lymphatic endothelial cells and stroma}

As was mentioned above, the growth of tumor-associated LECs requires an anchorable and permissive stroma (88). Tethering to the surrounding tissue through anchoring filament is necessary for LEC survival within the tumor stroma (137). Interestingly, the integrin on LEC can not only bind to the extracellular filament, but also be activated by lymphangiogenic VEGF-C/D to induce activation of downstream signaling pathways and promotion of LEC migration (138). However, it is another question to explore as to whether integrin's binding to ECM protein, such as fibronectin, can also induce the lymphangiogenic effects seen in the case of VEGF-C/D. Moreover, hyaluronic acid (HA), which can act on the HA receptor LYVE-1 in LECs, is another lymphangiogenic factor derived from ECM (139). It can enhance LEC proliferation and migration, but this effect needs to be further determined in the microenvironment of the tumor. Indeed, a hyaluronan-rich tumor micro-environment would significantly promote intratumoural lymphangiogenesis (140).

During the progression of cancer, the stroma can see a great infiltration of cancer-associated fibroblasts (CAFs). Apart from their role in producing collagen and fibrin, 
CAFs are a known source of angiogenic factors (141), promoting tumor-associated angiogenesis. Additionally, their presence is correlated with the LVD and tumor LN metastasis $(142,143)$. Indeed, recent evidence convinced that CAFs could secrete the powerful VEGF-C, as well as other lymphangiogenic factors, such as HGF and PDGF, to induce tumor-associated LEC proliferation $(73,144,145)$, adding to the sustaining role of tumor stroma for LEC survival and growth. In consistence with this, factors that can induce the secretion of VEGF-C from CAFs, such as the tumor cell-derived lysyl oxidase-like protein 2 (LOXL2), also lead to increased lymphangiogenesis and LN metastasis (146).

Concerning the role of lymphatics in draining interstitial fluid, tumor-associated lymphangiogenesis is bound to be affected by the interstitial fluid pressure (IFP), in addition to the ECM proteins. As a consequence of leaky capillaries and densely packed tumor cells, IFP gradient elevation is frequently seen due to fluid accumulation. Indeed, increased IFP can directly increase tumor lymphangiogenesis (147). This can be directly through the activation of VEGFR-3 signaling (148) or indirectly through the generation and maintenance of CAFs or TAMs (149-151). Indeed, the force sensor Piezo1 is identified recently in the mechanotransduction pathway, which may control the development of lymphatic valves (152).

Also, LECs may also exert some effects on stroma remodeling in return, making their interaction a bidirectional play (Figure 3). Frequently observed in clinics, dysfunctional lymphatics can result in lymphedema (153). Concerning the role of lymphatic vessels in draining interstitial fluid, increased lymphangiogenesis is bound to reduce interstitial pressure (53), which may favor nutrition influx and then tumor growth. Moreover, CCl19 and CCL2 1 that can be secreted from LECs have been found to promote fibroblast differentiation $(154,155)$. Immunofluorescence staining then further confirmed their spatial neighboring and thus close physical interaction (155). But still, it is unclear whether LEC might be able to promote CAF growth when it comes to tumor microenvironment.

\section{Role of lymphatic endothelial cells in tumor immunity}

Though having come into notice only recently, we now know that there can be a complex interaction between immune cells and LECs, both in the periphery and in TDLNs (Figure 3). These mutual interactions can shape the tumor immune micro-environment and are strongly dependent on the specific context (6).

Similar to their role in the induction of tumor cell spreading, LECs form the conduits for immune cell trafficking as well. This is through the production of chemokines, which will guide the homing of APCs to initiate anti-tumor immunity in TDLNs (8). For example, CC-chemokine ligand 21 (CCL21), which is expressed constitutively by tumor-associated LECs, can be immobilized by heparin sulfate in ECM to generate haptotactic gradients (156). The secreted CCL21 then interacts with its receptor CCR7 expressed on the surface of DCs to facilitate their entry into the lymphatic vessels (157). The antigen-loaded DCs can then get in contact with T cells in LNs to facilitate their priming and initiate antigenspecific immunity (158). Similarly, CCL21 may guide the homing of naive, memory, and regulatory $\mathrm{T}$ cells, which also express CCR7, from the periphery back to LN (159). It is also interesting that Regulatory $\mathrm{T}$ cells (Tregs) may use lymphotoxins (LTs), which can act on the LT $\beta$ receptor (LT $\beta R$ ) on LECs, to induce the production of chemotactic molecules and facilitate their transendothelial migration (160). It should also be noted that the local signaling microenvironment in TDLNs can determine the quality of induced immune response by shaping the phenotype of recruited leukocytes process of antigen presenting, making it either immunogenic or tolerogenic (161).

Moreover, in the draining LNs, ceiling LECs of subcapsular sinus may scavenge the CCR7 ligands with the help of atypical chemokine receptor CCRL1 (162), and the floor LECs can secrete CCL1 to act on its receptor CCR8 in DCs (163). These together create a chemokine gradient across the subcapsular sinus towards the subcapsular floor, facilitating the emigration of DCs towards LN parenchyma. Consequently, much fewer infiltrated inflammatory immune cells were seen in melanoma xenografts of transgenic mice lacking LECs. This emphasizes the essential role of LECs in the modulation of anti-tumor immunity and communication between primary tumor and TDLNs (83) again, even though the process of effector cells transporting towards peripheral lymphatics is still somewhat elusive. Research showed that S1P produced by Sphk in LN is essential for lymphatic vasculature remodeling and $\mathrm{T}$ cell egressing from LNs $(164,165)$. Acting on the Sphingosine 1-phosphate type 1 receptor (S1PR1), it can modulate LEC junctional stability of medullary sinus and facilitate lymphocyte transendothelial migration $(166,167)$. Activated lymphocytes then transverse from LN parenchyma to 
medullary sinus, which then follow the flow of lymphatic fluid to efferent lymphatics and later back to the circulatory system through connection by thoracic duct. However, further work is called for to elucidate the complex interaction involved in lymphocyte egressing from LNs and other roles that LECs may play in this process.

Apart from the antigens loaded by APCs patrolling in peripheral lymphatics, small antigens may be driven to TDLNs directly by the force of the interstitial flow of lymphatic vessels (168). Some of these antigens can be loaded by resident APCs in the subcapsular sinus (169). In contrast, others with certain molecular weight can transverse directly across the floor LECs into the LN parenchyma. This is achieved through some specialized pathways, such as the transendothelial channels and adjacent reticular conduits for molecules that are less than $70 \mathrm{kDa}(170,171)$, and the active transcytosis process, which is dynamin-dependent for some larger molecules (172). These can then allow the entrance of antigens into the LN parenchyma well before the influx of antigen-loaded migratory DCs (8). However, we still do not know to how much extent the LEC-aided transmigration could affect the case of tumor-antigen and anti-tumor immunity.

Concerning the high phagocytic and endocytic capacities of LECs, it is no wonder that they can efficiently sample the exogenous antigens. Indeed, they can efficiently archive the captured antigens following vaccination and viral infection (173), which will later be exchanged with migratory DCs and cross-presented to circulating $\mathrm{T}$ cells (174), resulting in a pool of memory $\mathrm{CD} 8^{+} \mathrm{T}$ cells with increased effector function and protective capacity. However, this antigen archiving capacity may also need to be validated in the case of anti-tumor immunity.

Moreover, LECs may themselves serve as unprofessional APCs (6). Though MHC-I and MHC-II are constitutively expressed on LN LECs, a lack of costimulatory factors, such as $\mathrm{H} 2-\mathrm{M}$, and high expression of inhibitory factors, such as PD-L1, can lead to induction of tolerogenic $\mathrm{CD}^{+} \mathrm{T}$ cells during LEC-aided antigen-presenting $(175,176)$. Similar to the case with LN LECs, peripheral LECs can also express a high level of PD-L1 to limit T cell activation, which may be due to the IFN- $\gamma$ released in the tumor microenvironment $(177,178)$. This IFN- $\gamma$ effect on LEC is somewhat similar to its induction of PD-L1 in tumor or immune cells, as is often seen in the resolution of anti-tumor immunity. Moreover, both LN and peripheral LECs can cross-present scavenged tumor antigens. This cross-presentation leads to apoptosis and dysfunction of tumor-antigen-specific $\mathrm{T}$ cell and failure of anti-tumor immunity $(110,179)$.

In addition to direct induction of tolerance through antigen-presenting, LECs can express immune suppressive factors to modulate effector cell function indirectly. For example, LN LECs express nitric oxide synthase 2 (NOS2) to produce nitric oxide, leading to the dampening of $\mathrm{T}$ cell proliferation (180). Similarly, they can produce indoleamine2,3-dioxygenases for tryptophan depletion, resulting in the dysfunction of effector immune cells (181). Moreover, LECs can modulate the maturation and function of DCs through binding of Mac-1 on DCs via ICAM-1, leading to decreased expression of the costimulatory molecule CD86 by DCs and suppressed ability to induce $\mathrm{T}$ cell proliferation (182). However, it should be noted that LECs can also secrete immunogenic IL-7 and IL-33. These factors can then provide the antiapoptotic and proliferative signals for $\mathrm{T}$ cell activation $(183,184)$. These, in turn, add to the complexity of the regulation of anti-tumor immunity by LECs.

Moreover, recent evidence convinced that there exists bidirectional cross-talk between LECs and immune cells (6). Apart from the VEGF-C producing leukocytes that may be recruited under pathological conditions $(61,81,84,185,186)$, other secreted factors, such as lipocalin 2 (LCN2) from macrophages, are also found to be lymphangiogenic (187). Much in an indirect way, the LT-LT $\beta R$ interaction between $\mathrm{B}$ cells and fibroblastic reticular cells (FRCs) can lead to increased production of lymphangiogenic factors in $\mathrm{B}$ cells caused by increased B-cell-activating factor (BAFF) from FRCs (188). Moreover, the cytokines that infiltrating immune cells produce can have a direct effect on LEC proliferation, migration, and tube formation. For example, IFN- $\gamma$ secreted by Th1 cells, or IL-4 and IL- 13 secreted by Th2 cells, can directly inhibit the transcription factor Prox1 expression and negatively regulate lymphangiogenesis $(189,190)$. On the other hand, IL-17 secreted from Th17 cells can indeed induce the proliferation of LECs (191). These regulations of lymphangiogenesis from immune cells offer a way for the homeostasis of the local immune response, concerning the role of LEC in the transport and recruitment of leukocytes, although the roles of leukocytederived cytokines in the tumor micro-environment have not been fully determined.

In addition to producing lymphangiogenic factors, infiltrating TAMs can indeed transdifferentiate into LECs under pathogenic conditions (41). Inhibiting TAM infiltration through blocking CSF-1 pathway efficiently 
reduced tumor lymphangiogenesis (192), and this can only partly be explained by their secretion of lymphangiogenic factors (43). This population of LEC progenitor cells, which are called M-LECP as was mentioned, are derived from bone marrow precursors of the monocyte-macrophage lineage, and characterized by the co-expression of markers for LECs, stem cells, M2-type macrophages, and myeloidderived immunosuppressive cells $(193,194)$. They can be incorporated into LECs, acting as a direct structural contributor to the newly formed lymphatics (195). This integration is shown to be mediated by the activation of integrin $\beta 1$ by galectin 8 (GAL8) derived from LECs (196). As this integration is only found under disease condition, adding more importance to their role in tumor lymphangiogenesis. The recruitment of M-LECP to TME may be through the CSF-1 (43,192), VEGF-A $(197,198)$, CXCL12 (199) acting on their corresponding receptors.

\section{Special focus on lung cancer}

While initial evidence for the correlation between lymphangiogenesis and cancer prognosis has come from the studies of melanoma and breast cancer $(13,200)$, similar results were then found in non-small cell lung cancer as well $(10,201)$. On the one hand, VEGF-C staining intensity is correlated with LVD, LN metastasis, and patient survival in lung adenocarcinoma (56,202-204). On the other hand, the up-regulation of VEGF-D induced by IL-7/IL-7R interaction correlates well with the LVD, clinical stage, and poor prognosis of NSCLC patients (205). Indeed, miRNAs that target VEGF-C could significantly suppress lymphangiogenesis of tumor xenografts (206). Moreover, drugs that downregulated VEGF-C expression in NSCLC tumor tissue can, in turn, reduce the number of pleural tumor foci and volume of pleural effusion, possibly through decreasing tumor lymphangiogenesis (207). Thus the lymphangiogenic factors may increase NSCLC progression through increased tumor-associated lymphangiogenesis, though they themselves may have direct proliferationpromoting effects on the lung cancer cells (208).

Similar results were also seen for the other side of the VEGF-C/D-VEGFR-3 axis. Through immunochemistry staining, VEGFR-3-positive endothelial cell density is shown to be a significant prognostic factor in NSCLC (209). Indeed, the co-expression of other lymphangiogenic factors, including FGF2 and PDGF-B, and VEGFR-3, is also shown to be strongly associated with poor survival in NSCLC patients $(210,211)$.

\section{Possible therapeutic targets for cancer based on LECs}

Though the therapeutic effect of anti-neovascularization has been revealed in the clinic, therapies aiming at tumor lymphangiogenesis have gained attention only in recent years (212). The rationale behind anti-lymphangiogenesis therapy is based on the possible effect of restricting tumor cell metastasis to LNs and later distant organs. Also, concerning the immune regulatory function and tumor sustaining roles of LECs, the anti-lymphangiogenesis therapies may offer extra benefit (Table 1).

With the central role of the VEGF-C/D-VEGFR-3 axis in the generation of tumor-associated lymphangiogenesis, therapies have been designed mainly for targeting this pathway currently. VEGFR-3 contains an extracellular segment with immunoglobulin-like domains, a transmembrane segment, a juxtamembrane segment, a protein kinase domain, and a C-terminal tail. Thus, smallmolecule inhibitors of the protein kinase domain have been designed. Small molecules with VEGFR-3 protein kinase inhibiting effects, such as sunitinib, pazopanib, sorafenib, axitinib, cabozantinib and lenvatinib have been approved for the treatment of renal cell carcinoma (RCC), soft-tissue carcinoma, hepatocellular carcinoma, or pancreatic neuroendocrine tumors (PanNETs), thyroid cancer and gastrointestinal stromal tumor (GIST) (216-218,220,221,223-226,228-231,239), though their effects in inhibiting tumor-associated lymphangiogenesis have not been fully elucidated $(219,222,227)$. However, their efficacy in NSCLC has not been fully determined. Also, specific inhibitors of VEGFR-3 protein kinase may also be needed to be developed in the future. With the approval of clinical use of monoclonal antibody (mAb) Bevacizumab that neutralizes VEGF-A for efficient inhibition of tumor neovascularization, mAbs that can target VEGF-C/D or the extracellular domain of VEGFR-3 have also been designed $(213-215,232,233,240)$. However, these are still in their preclinical stage, with further work to be done before clinical use. Moreover, concerning the failure of clinical trials that use bevacizumab as a single agent, the proposal of anti-VEGF-C therapy should gain more caution, and the combined therapy with other drugs directly targeting tumor cells may bear a better chance of success.

Drugs targeting other signaling pathways involved in tumor lymphangiogenesis, such as the ANGPT2-Tie2, and NRP-2, are also available now $(58,234,236,241,242)$. Nevertheless, again, it is still a long way before the 
Table 1 Possible therapeutic targets for cancer based on LECs

\begin{tabular}{|c|c|c|c|c|c|}
\hline $\begin{array}{l}\text { Molecular } \\
\text { targets }\end{array}$ & Drugs & Class of drugs & Therapeutic effects on LECs & Clinical status & Types of cancer \\
\hline \multirow[t]{2}{*}{ VEGF-C/D } & VGX-100 (213) & $\begin{array}{l}\text { VEGF-C monoclonal } \\
\text { antibody }\end{array}$ & $\begin{array}{l}\text { Inhibiting LEC in mouse } \\
\text { lymphangiogenesis model (213) }\end{array}$ & Preclinical & - \\
\hline & VD1 (214) & $\begin{array}{l}\text { VEGF-D monoclonal } \\
\text { antibody }\end{array}$ & $\begin{array}{l}\text { Inhibiting VEGF-D-VEGFR-3 } \\
\text { binding (214) }\end{array}$ & Preclinical & - \\
\hline \multirow[t]{5}{*}{ VEGFR-3 } & $\begin{array}{l}\text { Sunitinib (216- } \\
218)\end{array}$ & Small molecular TKI & $\begin{array}{l}\text { Inhibiting lymphatic metastasis in } \\
\text { mouse tumor model (219) }\end{array}$ & $\begin{array}{l}\text { Approved for anti- } \\
\text { neoplastic use }\end{array}$ & RCC, PanNET, GIST \\
\hline & $\begin{array}{l}\text { Pazopanib } \\
(220,221)\end{array}$ & Small molecular TKI & $\begin{array}{l}\text { Inhibiting lymphatic metastasis in } \\
\text { mouse tumor model (222) }\end{array}$ & $\begin{array}{l}\text { Approved for anti- } \\
\text { neoplastic use }\end{array}$ & $\begin{array}{l}\text { RCC, soft-tissue } \\
\text { sarcoma }\end{array}$ \\
\hline & $\begin{array}{l}\text { Cabozantinib } \\
(228,229)\end{array}$ & Small molecular TKI & $\begin{array}{l}\text { Unproved effects on } \\
\text { lymphangiogenesis }\end{array}$ & $\begin{array}{l}\text { Approved for anti- } \\
\text { neoplastic use }\end{array}$ & $\begin{array}{l}\mathrm{RCC}, \text { medullary } \\
\text { thyroid carcinoma }\end{array}$ \\
\hline & $\begin{array}{l}\text { Lenvatinib } \\
(225,230,231)\end{array}$ & Small molecular TKI & $\begin{array}{l}\text { Unproved effects on } \\
\text { lymphangiogenesis }\end{array}$ & $\begin{array}{l}\text { Approved for anti- } \\
\text { neoplastic use }\end{array}$ & $\begin{array}{l}\mathrm{RCC}, \mathrm{HCC} \text {, thyroid } \\
\text { carcinoma }\end{array}$ \\
\hline & hF4-3C5 (232) & $\begin{array}{l}\text { Monoclonal } \\
\text { antibody }\end{array}$ & $\begin{array}{l}\text { Inhibiting lymphatic metastasis in } \\
\text { mouse tumor model (233) }\end{array}$ & $\begin{array}{l}\text { Phase I } \\
\text { (NCT01288989) (232) }\end{array}$ & $\begin{array}{l}\text { Advanced solid } \\
\text { tumors, CRC }\end{array}$ \\
\hline ANGPT2-Tie2 & Regorafenib (234) & Small molecular TKI & $\begin{array}{l}\text { Inhibiting lymphatic metastasis in } \\
\text { mouse tumor model (235) }\end{array}$ & $\begin{array}{l}\text { Approved for anti- } \\
\text { neoplastic use }\end{array}$ & CRC, GIST, HCC \\
\hline NRP-2 & anti-Nrp2B (58) & $\begin{array}{l}\text { Monoclonal } \\
\text { antibody }\end{array}$ & $\begin{array}{l}\text { Inhibiting lymphatic metastasis in } \\
\text { mouse tumor model (58) }\end{array}$ & Preclinical & - \\
\hline \multirow[t]{2}{*}{$\operatorname{cox} 2$} & Etodolac (30) & NSAIDS & $\begin{array}{l}\text { Contracting collecting vessel in } \\
\text { mouse tumor model }(30)\end{array}$ & $\begin{array}{l}\text { Approved for anti- } \\
\text { inflammatory use }\end{array}$ & Breast cancer \\
\hline & Indomethacin (55) & NSAIDS & $\begin{array}{l}\text { Contracting collecting vessel in } \\
\text { mouse tumor model (55) }\end{array}$ & $\begin{array}{l}\text { Approved for anti- } \\
\text { inflammatory use }\end{array}$ & Breast cancer \\
\hline
\end{tabular}

actual clinical use. As the ANGPT2-Tie2 and the NRP2 signaling may promote cancer progression beyond their lymphangiogenesis role, it also needs to be determined whether the beneficial effects of blocking these pathways are through tumor-associated lymphatics $(235,238,243)$. Interestingly, nonsteroidal anti-inflammatory drugs (NSAIDs), which are known inhibitors of prostaglandin synthesis induced by VEGF-D, can effectively reduce collecting lymphatic vessel dilation and subsequent LN metastasis (29). This implies that NSAIDs may be used as an adjuvant in anti-lymphangiogenesis therapy.

Recently, the concept of tumor vessel normalization has gained attention (244). Through anti-angiogenic drugs, normalization of vessel permeability can reduce the 
leakage of vascular fluid, leading to the downregulation of interstitial pressure-induced lymphangiogenesis $(237,245)$. Also, this raised the question of a similar normalization of tumor-associated lymphatics. Indeed, by inhibiting the LEC autophagy and permeability caused by paclitaxel, chloroquine reduces tumor cell LN metastasis and increases treatment efficacy (115). In this sense, the therapeutic effects of drugs that may increase LEC junction and reduce the caliber of lymphatic vessels are needed to be tested in future studies.

\section{Unsolved problems and future directions}

Though it has been shown from clinical studies that LN metastasis is an indicator of a worse prognosis of cancers, there have long been questions about whether it mediates systematic metastasis or just manifests tumor dissemination. While peripheral LECs at the tumor site can form draining conduits for tumor cells, they are also needed for immune cell traffic in the anti-tumor immune response. Though LECs at draining LNs can secrete chemokines for antigenloaded APC homing, these factors can also induce tumor cell chemotaxis and LN metastasis. Moreover, functioning as unprofessional APCs themselves, the type of immune response it induces can be highly dependent on the local micro-environment. Thus, therapies targeting LECs and tumor-associated lymphangiogenesis should differentiate the bad verse good effects of LECs.

Concerning the future research direction on tumorassociated LECs, the interaction between LECs and multiple other cell populations should be the focus. On the one hand, it is now clear that LECs and other cell populations can reach spatial proximity through chemoattractant, including CCL19, CCL21. However, whether there exist other types of chemoattractants and what specific cell populations they can act on remains to be answered. On the other hand, while we know now that LECs can play an active role in tumor micro-environment by producing growth factors to sustain tumor cell or present tumor-antigens to the immune cells, more details need to be revealed on the cellular and molecular mechanism involved, through which future therapies may be designed.

Thus, it also suggests that several distinct subpopulations of LECs exist, which may fulfill diverse types of functions. The recent advance of single-cell RNA sequence indeed revealed disparate populations of LECs in LNs (49), however, more research is needed as to whether subpopulations of LECs could be involved in different aspects of anti-tumor immunity and related to the sequential steps of tumor metastasis. Moreover, the detailed underlying mechanisms for the differentiation and regulation of LECs call for more exploration. In this sense, drugs targeting the specific markers of pro-tumor LECs, and reservation of LECs that may restrain tumor cell, should be a better approach for controlling lymphangiogenesis-aided tumor metastasis.

\section{Summary}

In this manuscript, we summarized the recent advances LECs' role in the tumor microenvironment, including cancer progression and tumor drug therapy. We then discussed their interaction with different cell populations in the tumor microenvironment, and possible targets for cancer therapies based on LECs. While we now know that LECs can play a much more complex role than simply forming the conduits of tumor cell dissemination, more research is needed to decipher the mechanisms involved, and effective therapies targeting tumor-associated lymphatics may be developed in future.

\section{Acknowledgments}

We thank Juanjuan Long for helping with the graphics. Funding: This work was supported by the following funding: China National Science Foundation (Grant No. 81871893 \& No. 81501996); Key Project of Guangzhou Scientific Research Project (Grant No. 201804020030); National Key Technology R\&D Program (2018YFC1311900), Guangdong Science and Technology Foundation (2019B030316028).

\section{Footnote}

Reporting Checklist: The authors have completed the Narrative Review reporting checklist. Available at http:// dx.doi.org/10.21037/tlcr-21-40

Peer Review File: Available at http://dx.doi.org/10.21037/ tlcr-21-40

Conflicts of Interest: All authors have completed the ICMJE uniform disclosure form (available at http://dx.doi. org/10.21037/tlcr-21-40). Wenhua Liang serves as an unpaid Associate Editor-in-Chief of Translational Lung Cancer Research from Apr 2018 - Apr 2021. The other 
authors have no conflicts of interest to declare.

Ethical Statement: The authors are accountable for all aspects of the work in ensuring that questions related to the accuracy or integrity of any part of the work are appropriately investigated and resolved.

Open Access Statement: This is an Open Access article distributed in accordance with the Creative Commons Attribution-NonCommercial-NoDerivs 4.0 International License (CC BY-NC-ND 4.0), which permits the noncommercial replication and distribution of the article with the strict proviso that no changes or edits are made and the original work is properly cited (including links to both the formal publication through the relevant DOI and the license). See: https://creativecommons.org/licenses/by-nc-nd/4.0/.

\section{References}

1. Mikada M, Sukhbaatar A, Miura Y, et al. Evaluation of the enhanced permeability and retention effect in the early stages of lymph node metastasis. Cancer Sci2017;108:846-52.

2. Stacker SA, Williams S, Karnezis T, et al. Lymphangiogenesis and lymphatic vessel remodelling in cancer. Nat Rev Cancer 2014;14:159-72.

3. Jiang X. Lymphatic vasculature in tumor metastasis and immunobiology. J Zhejiang Univ Sci B 2019;21:3-11.

4. Dieterich LC, Detmar M. Tumor lymphangiogenesis and new drug development. Adv Drug Deliv Rev 2016;99:148-60.

5. Lee BS, Jang JY, Seo C, et al. Crosstalk between head and neck cancer cells and lymphatic endothelial cells promotes tumor metastasis via CXCL5-CXCR2 signaling. Faseb j 2021;35:e21181.

6. Yeo KP, Angeli V. Bidirectional Crosstalk between Lymphatic Endothelial Cell and T Cell and Its Implications in Tumor Immunity. Front Immunol 2017;8:83.

7. Munir H, Mazzaglia C, Shields J. Stromal regulation of tumor-associated lymphatics. Adv Drug Deliv Rev 2020;161-162:75-89.

8. Jalkanen S, Salmi M. Lymphatic endothelial cells of the lymph node. Nat Rev Immunol 2020;20:566-78.

9. Yoshimatsu Y, Miyazaki H, Watabe T. Roles of signaling and transcriptional networks in pathological lymphangiogenesis. Adv Drug Deliv Rev 2016;99:161-71.

10. Renyi-Vamos F, Tovari J, Fillinger J, et al.
Lymphangiogenesis correlates with lymph node metastasis, prognosis, and angiogenic phenotype in human non-small cell lung cancer. Clin Cancer Res 2005;11:7344-53.

11. Dadras SS, Lange-Asschenfeldt B, Velasco P, et al. Tumor lymphangiogenesis predicts melanoma metastasis to sentinel lymph nodes. Mod Pathol 2005;18:1232-42.

12. Doekhie FS, Morreau H, de Bock GH, et al. Sialyl Lewis $\mathrm{X}$ expression and lymphatic microvessel density in primary tumors of node-negative colorectal cancer patients predict disease recurrence. Cancer Microenviron 2008;1:141-51.

13. Zhang S, Zhang D, Gong M, et al. High lymphatic vessel density and presence of lymphovascular invasion both predict poor prognosis in breast cancer. BMC Cancer 2017;17:335.

14. Skobe M, Hawighorst T, Jackson DG, et al. Induction of tumor lymphangiogenesis by VEGF-C promotes breast cancer metastasis. Nat Med 2001;7:192-8.

15. Mandriota SJ, Jussila L, Jeltsch M, et al. Vascular endothelial growth factor-C-mediated lymphangiogenesis promotes tumour metastasis. EMBO J 2001;20:672-82.

16. Leu AJ, Berk DA, Lymboussaki A, et al. Absence of functional lymphatics within a murine sarcoma: a molecular and functional evaluation. Cancer Res 2000;60:4324-7.

17. Padera TP, Kadambi A, di Tomaso E, et al. Lymphatic metastasis in the absence of functional intratumor lymphatics. Science 2002;296:1883-6.

18. Tammela T, Alitalo K. Lymphangiogenesis: Molecular mechanisms and future promise. Cell 2010;140:460-76.

19. Sainte-Marie G. The lymph node revisited: development, morphology, functioning, and role in triggering primary immune responses. Anat Rec (Hoboken) 2010;293:320-37.

20. Louie DAP, Liao S. Lymph Node Subcapsular Sinus Macrophages as the Frontline of Lymphatic Immune Defense. Front Immunol 2019;10:347.

21. Gerner MY, Torabi-Parizi P, Germain RN. Strategically localized dendritic cells promote rapid $\mathrm{T}$ cell responses to lymph-borne particulate antigens. Immunity 2015;42:172-85.

22. Moran I, Grootveld AK, Nguyen A, et al. Subcapsular Sinus Macrophages: The Seat of Innate and Adaptive Memory in Murine Lymph Nodes. Trends in Immunology 2019;40:35-48.

23. Mondor I, Baratin M, Lagueyrie M, et al. Lymphatic Endothelial Cells Are Essential Components of the Subcapsular Sinus Macrophage Niche. Immunity 2019;50:1453-66.e4.

24. Brown M, Assen FP, Leithner A, et al. Lymph node 
blood vessels provide exit routes for metastatic tumor cell dissemination in mice. Science 2018;359:1408-11.

25. Sainte-Marie G, Peng FS, Bélisle C. Overall architecture and pattern of lymph flow in the rat lymph node. Am J Anat 1982;164:275-309.

26. Grigorova IL, Panteleev M, Cyster JG. Lymph node cortical sinus organization and relationship to lymphocyte egress dynamics and antigen exposure. Proc Natl Acad Sci U S A 2010;107:20447-52.

27. Holopainen T, Saharinen P, D'Amico G, et al. Effects of angiopoietin-2-blocking antibody on endothelial cellcell junctions and lung metastasis. J Natl Cancer Inst 2012;104:461-75.

28. Clasper S, Royston D, Baban D, et al. A novel gene expression profile in lymphatics associated with tumor growth and nodal metastasis. Cancer Res 2008;68:7293-303.

29. Karnezis T, Shayan R, Caesar C, et al. VEGF-D promotes tumor metastasis by regulating prostaglandins produced by the collecting lymphatic endothelium. Cancer Cell 2012;21:181-95.

30. Gogineni A, Caunt M, Crow A, et al. Inhibition of VEGF-C modulates distal lymphatic remodeling and secondary metastasis. PLoS One 2013;8:e68755.

31. Mäkinen T, Veikkola T, Mustjoki S, et al. Isolated lymphatic endothelial cells transduce growth, survival and migratory signals via the VEGF-C/D receptor VEGFR-3. EMBO J 2001;20:4762-73.

32. Cao R, Björndahl MA, Religa P, et al. PDGF-BB induces intratumoral lymphangiogenesis and promotes lymphatic metastasis. Cancer Cell 2004;6:333-45.

33. Pereira ER, Kedrin D, Seano G, et al. Lymph node metastases can invade local blood vessels, exit the node, and colonize distant organs in mice. Science 2018;359:1403-7.

34. Achen MG, Stacker SA. Exit Stage Left: A Tumor Cell's Journey from Lymph Node to Beyond. Trends Cancer 2018;4:519-22.

35. Wigle JT, Harvey N, Detmar M, et al. An essential role for Prox1 in the induction of the lymphatic endothelial cell phenotype. EMBO J 2002;21:1505-13.

36. Wigle JT, Oliver G. Prox1 function is required for the development of the murine lymphatic system. Cell 1999;98:769-78.

37. François M, Caprini A, Hosking B, et al. Sox18 induces development of the lymphatic vasculature in mice. Nature 2008;456:643-7.

38. Yoshimatsu Y, Yamazaki T, Mihira H, et al. Ets family members induce lymphangiogenesis through physical and functional interaction with Prox1. J Cell Sci 2011;124:2753-62.

39. Yoshimatsu Y, Lee YG, Akatsu Y, et al. Bone morphogenetic protein-9 inhibits lymphatic vessel formation via activin receptor-like kinase 1 during development and cancer progression. Proc Natl Acad Sci U S A 2013;110:18940-5.

40. Zheng $W$, Tammela T, Yamamoto $M$, et al. Notch restricts lymphatic vessel sprouting induced by vascular endothelial growth factor. Blood 2011;118:1154-62.

41. Ran S, Volk-Draper L. Lymphatic Endothelial Cell Progenitors in the Tumor Microenvironment. Adv Exp Med Biol 2020;1234:87-105.

42. Gutierrez-Miranda L, Yaniv K. Cellular Origins of the Lymphatic Endothelium: Implications for Cancer Lymphangiogenesis. Front Physiol 2020;11:577584.

43. Volk-Draper L, Patel R, Bhattarai N, et al. MyeloidDerived Lymphatic Endothelial Cell Progenitors Significantly Contribute to Lymphatic Metastasis in Clinical Breast Cancer. Am J Pathol 2019;189:2269-92.

44. Koltowska K, Betterman KL, Harvey NL, et al. Getting out and about: the emergence and morphogenesis of the vertebrate lymphatic vasculature. Development 2013;140:1857-70.

45. Banerji S, Ni J, Wang SX, et al. LYVE-1, a new homologue of the CD44 glycoprotein, is a lymph-specific receptor for hyaluronan. J Cell Biol 1999;144:789-801.

46. Breiteneder-Geleff S, Matsui K, Soleiman A, et al. Podoplanin, novel 43-kd membrane protein of glomerular epithelial cells, is down-regulated in puromycin nephrosis. Am J Pathol 1997;151:1141-52.

47. Wetterwald A, Hoffstetter W, Cecchini MG, et al. Characterization and cloning of the E11 antigen, a marker expressed by rat osteoblasts and osteocytes. Bone 1996;18:125-32.

48. Saad RS, Kordunsky L, Liu YL, et al. Lymphatic microvessel density as prognostic marker in colorectal cancer. Mod Pathol 2006;19:1317-23.

49. Takeda A, Hollmén M, Dermadi D, et al. Single-Cell Survey of Human Lymphatics Unveils Marked Endothelial Cell Heterogeneity and Mechanisms of Homing for Neutrophils. Immunity 2019;51:561-72.e5.

50. Stacker SA, Achen MG, Jussila L, et al. Lymphangiogenesis and cancer metastasis. Nat Rev Cancer 2002;2:573-83.

51. Mumprecht V, Detmar M. Lymphangiogenesis and cancer metastasis. J Cell Mol Med 2009;13:1405-16.

52. Stacker SA, Caesar C, Baldwin ME, et al. VEGF-D promotes the metastatic spread of tumor cells via the 
lymphatics. Nat Med 2001;7:186-91.

53. Karpanen T, Egeblad M, Karkkainen MJ, et al. Vascular endothelial growth factor $\mathrm{C}$ promotes tumor lymphangiogenesis and intralymphatic tumor growth. Cancer Res 2001;61:1786-90.

54. Niederleithner H, Heinz M, Tauber S, et al. Wnt1 is antilymphangiogenic in a melanoma mouse model. J Invest Dermatol 2012;132:2235-44.

55. Timoshenko AV, Chakraborty C, Wagner GF, et al. COX-2-mediated stimulation of the lymphangiogenic factor VEGF-C in human breast cancer. Br J Cancer 2006;94:1154-63.

56. Su JL, Shih J, Yen M, et al. Cyclooxygenase-2 induces EP1- and HER-2/Neu-dependent vascular endothelial growth factor-C up-regulation: a novel mechanism of lymphangiogenesis in lung adenocarcinoma. Cancer Res 2004;64:554-64.

57. Song J, Chen W, Cui X, et al. CCBE1 promotes tumor lymphangiogenesis and is negatively regulated by TGF $\beta$ signaling in colorectal cancer. Theranostics 2020;10:2327-41.

58. Caunt M, Mak J, Liang WC, et al. Blocking neuropilin-2 function inhibits tumor cell metastasis. Cancer Cell 2008;13:331-42.

59. Wang J, Huang Y, Zhang J, et al. NRP-2 in tumor lymphangiogenesis and lymphatic metastasis. Cancer Lett 2018;418:176-84.

60. Cao Y, Hoeppner LH, Bach S, et al. Neuropilin-2 promotes extravasation and metastasis by interacting with endothelial $\alpha 5$ integrin. Cancer Res 2013;73:4579-90.

61. Ji RC. Macrophages are important mediators of either tumor- or inflammation-induced lymphangiogenesis. Cell Mol Life Sci 2012;69:897-914.

62. Chen C, He W, Huang J, et al. LNMAT1 promotes lymphatic metastasis of bladder cancer via CCL2 dependent macrophage recruitment. Nat Commun 2018;9:3826.

63. Watari K, Shibata T, Kawahara A, et al. Tumor-derived interleukin-1 promotes lymphangiogenesis and lymph node metastasis through M2-type macrophages. PLoS One 2014;9:e99568.

64. Ji H, Cao R, Yang Y, et al. TNFR1 mediates TNF- $\alpha$ induced tumour lymphangiogenesis and metastasis by modulating VEGF-C-VEGFR3 signalling. Nat Commun 2014;5:4944.

65. Shin JW, Min M, Larrieu-Lahargue F, et al. Prox1 promotes lineage-specific expression of fibroblast growth factor (FGF) receptor-3 in lymphatic endothelium: a role for FGF signaling in lymphangiogenesis. Mol Biol Cell 2006;17:576-84.

66. Cao R, Ji H, Feng N, et al. Collaborative interplay between FGF-2 and VEGF-C promotes lymphangiogenesis and metastasis. Proc Natl Acad Sci U S A 2012;109:15894-9.

67. Bracher A, Cardona AS, Tauber S, et al. Epidermal growth factor facilitates melanoma lymph node metastasis by influencing tumor lymphangiogenesis. J Invest Dermatol 2013;133:230-8.

68. Gao P, Li C, Chang Z, et al. Carcinoma associated fibroblasts derived from oral squamous cell carcinoma promote lymphangiogenesis via c-Met/PI3K/AKT in vitro. Oncol Lett 2018;15:331-7.

69. Berenguer-Daizé C, Boudouresque F, Bastide C, et al. Adrenomedullin blockade suppresses growth of human hormone-independent prostate tumor xenograft in mice. Clin Cancer Res 2013;19:6138-50.

70. Fritz-Six KL, Dunworth WP, Li M, et al. Adrenomedullin signaling is necessary for murine lymphatic vascular development. J Clin Invest 2008;118:40-50.

71. Nagahashi M, Ramachandran S, Kim EY, et al. Sphingosine-1-phosphate produced by sphingosine kinase 1 promotes breast cancer progression by stimulating angiogenesis and lymphangiogenesis. Cancer Res 2012;72:726-35.

72. Lee AS, Kim DH, Lee JE, et al. Erythropoietin induces lymph node lymphangiogenesis and lymph node tumor metastasis. Cancer Res 2011;71:4506-17.

73. Gibot L, Galbraith T, Kloos B, et al. Cell-based approach for $3 \mathrm{D}$ reconstruction of lymphatic capillaries in vitro reveals distinct functions of $\mathrm{HGF}$ and VEGF-C in lymphangiogenesis. Biomaterials 2016;78:129-39.

74. Kajiya K, Hirakawa S, Ma B, et al. Hepatocyte growth factor promotes lymphatic vessel formation and function. EMBO J 2005;24:2885-95.

75. Fagiani E, Lorentz P, Kopfstein L, et al. Angiopoietin-1 and -2 exert antagonistic functions in tumor angiogenesis, yet both induce lymphangiogenesis. Cancer Res 2011;71:5717-27.

76. Karpinich NO, Kechele DO, Espenschied ST, et al. Adrenomedullin gene dosage correlates with tumor and lymph node lymphangiogenesis. FASEB J 2013;27:590-600.

77. Yoon CM, Hong BS, Moon HG, et al. Sphingosine-1phosphate promotes lymphangiogenesis by stimulating S1P1/Gi/PLC/Ca2 + signaling pathways. Blood 2008;112:1129-38.

78. Kim KE, Koh YJ, Jeon BH, et al. Role of CD11b+ macrophages in intraperitoneal lipopolysaccharide-induced 
aberrant lymphangiogenesis and lymphatic function in the diaphragm. Am J Pathol 2009;175:1733-45.

79. Kataru RP, Jung K, Jang C, et al. Critical role of $\mathrm{CD} 11 \mathrm{~b}+$ macrophages and VEGF in inflammatory lymphangiogenesis, antigen clearance, and inflammation resolution. Blood 2009;113:5650-9.

80. Baluk P, Hogmalm A, Bry M, et al. Transgenic overexpression of interleukin-1 $\beta$ induces persistent lymphangiogenesis but not angiogenesis in mouse airways. Am J Pathol 2013;182:1434-47.

81. Baluk P, Yao LC, Feng J, et al. TNF-alpha drives remodeling of blood vessels and lymphatics in sustained airway inflammation in mice. J Clin Invest 2009;119:2954-64.

82. Ristimäki A, Narko K, Enholm B, et al. Proinflammatory cytokines regulate expression of the lymphatic endothelial mitogen vascular endothelial growth factor-C. J Biol Chem 1998;273:8413-8.

83. Hos D, Bucher F, Regenfuss B, et al. IL-10 Indirectly Regulates Corneal Lymphangiogenesis and Resolution of Inflammation via Macrophages. Am J Pathol 2016;186:159-71

84. Weichand B, Popp R, Dziumbla S, et al. S1PR1 on tumor-associated macrophages promotes lymphangiogenesis and metastasis via NLRP3/IL-1 $\beta$. J Exp Med 2017;214:2695-713.

85. Shinriki S, Jono H, Ueda $M$, et al. Interleukin-6 signalling regulates vascular endothelial growth factor-C synthesis and lymphangiogenesis in human oral squamous cell carcinoma. J Pathol 2011;225:142-50.

86. Van der Auwera I, Van Laere SJ, Van den Eynden GG, et al. Increased angiogenesis and lymphangiogenesis in inflammatory versus noninflammatory breast cancer by real-time reverse transcriptase-PCR gene expression quantification. Clin Cancer Res 2004;10:7965-71.

87. Van der Auwera I, Van den Eynden GG, Colpaert CG, et al. Tumor lymphangiogenesis in inflammatory breast carcinoma: a histomorphometric study. Clin Cancer Res 2005;11:7637-42.

88. Wiig H, Keskin D, Kalluri R. Interaction between the extracellular matrix and lymphatics: consequences for lymphangiogenesis and lymphatic function. Matrix Biol 2010;29:645-56.

89. Clavin NW, Avraham T, Fernandez J, et al. TGFbeta 1 is a negative regulator of lymphatic regeneration during wound repair. Am J Physiol Heart Circ Physiol 2008;295:H2113-27.

90. Vainionpää N, Bützow R, Hukkanen M, et al.
Basement membrane protein distribution in LYVE-1immunoreactive lymphatic vessels of normal tissues and ovarian carcinomas. Cell Tissue Res 2007;328:317-28.

91. Ruoslahti E. Fibronectin and its integrin receptors in cancer. Adv Cancer Res 1999;76:1-20.

92. Garmy-Susini B, Avraamides CJ, Schmid MC, et al. Integrin alpha4beta 1 signaling is required for lymphangiogenesis and tumor metastasis. Cancer Res 2010;70:3042-51.

93. Galvagni F, Pennacchini S, Salameh A, et al. Endothelial cell adhesion to the extracellular matrix induces c-Srcdependent VEGFR-3 phosphorylation without the activation of the receptor intrinsic kinase activity. Circ Res 2010;106:1839-48.

94. Iwasaki T, Takeda Y, Maruyama K, et al. Deletion of tetraspanin CD9 diminishes lymphangiogenesis in vivo and in vitro. J Biol Chem 2013;288:2118-31.

95. Detry B, Erpicum C, Paupert J, et al. Matrix metalloproteinase-2 governs lymphatic vessel formation as an interstitial collagenase. Blood 2012;119:5048-56.

96. Wong HL, Jin G, Cao R, et al. MT1-MMP sheds LYVE1 on lymphatic endothelial cells and suppresses VEGF-C production to inhibit lymphangiogenesis. Nat Commun 2016;7:10824.

97. Oka M, Iwata C, Suzuki HI, et al. Inhibition of endogenous TGF-beta signaling enhances lymphangiogenesis. Blood 2008;111:4571-9.

98. Derynck R, Akhurst RJ. BMP-9 balances endothelial cell fate. Proc Natl Acad Sci U S A 2013;110:18746-7.

99. Sleeman JP, Thiele W. Tumor metastasis and the lymphatic vasculature. Int J Cancer 2009;125:2747-56.

100. Kerjaschki D. The lymphatic vasculature revisited. J Clin Invest 2014;124:874-7.

101.Dadras SS, Paul T, Bertoncini J, et al. Tumor lymphangiogenesis: a novel prognostic indicator for cutaneous melanoma metastasis and survival. Am J Pathol 2003;162:1951-60.

102. Kim M, Koh YJ, Kim KE, et al. CXCR4 signaling regulates metastasis of chemoresistant melanoma cells by a lymphatic metastatic niche. Cancer Res 2010;70:10411-21.

103. Cabioglu N, Yazici MS, Arun B, et al. CCR7 and CXCR4 as novel biomarkers predicting axillary lymph node metastasis in T1 breast cancer. Clin Cancer Res 2005;11:5686-93.

104. Shields JD, Fleury ME, Yong C, et al. Autologous chemotaxis as a mechanism of tumor cell homing to lymphatics via interstitial flow and autocrine CCR7 signaling. Cancer Cell 2007;11:526-38. 
105.Das S, Sarrou E, Podgrabinska S, et al. Tumor cell entry into the lymph node is controlled by CCL1 chemokine expressed by lymph node lymphatic sinuses. J Exp Med 2013;210:1509-28.

106. Miteva DO, Rutkowski JM, Dixon JB, et al. Transmural flow modulates cell and fluid transport functions of lymphatic endothelium. Circ Res 2010;106:920-31.

107.Lund AW, Wagner M, Fankhauser M, et al. Lymphatic vessels regulate immune microenvironments in human and murine melanoma. J Clin Invest 2016;126:3389-402.

108. Thomas SN, Rutkowski JM, Pasquier M, et al. Impaired humoral immunity and tolerance in K14-VEGFR-3Ig mice that lack dermal lymphatic drainage. J Immunol 2012;189:2181-90.

109. Cohen JN, Guidi CJ, Tewalt EF, et al. Lymph noderesident lymphatic endothelial cells mediate peripheral tolerance via Aire-independent direct antigen presentation. J Exp Med 2010;207:681-8.

110.Lund AW, Duraes FV, Hirosue S, et al. VEGF-C promotes immune tolerance in B16 melanomas and crosspresentation of tumor antigen by lymph node lymphatics. Cell Rep 2012;1:191-9.

111. Karaman S, Detmar M. Mechanisms of lymphatic metastasis. J Clin Invest 2014;124:922-8.

112. Hirakawa S. From tumor lymphangiogenesis to lymphvascular niche. Cancer Sci 2009;100:983-9.

113. González-González A, González A, Rueda N, et al. Usefulness of melatonin as complementary to chemotherapeutic agents at different stages of the angiogenic process. Sci Rep 2020;10:4790.

114. Harris AR, Perez MJ, Munson JM. Docetaxel facilitates lymphatic-tumor crosstalk to promote lymphangiogenesis and cancer progression. BMC Cancer 2018;18:718.

115.Zamora A, Alves M, Chollet C, et al. Paclitaxel induces lymphatic endothelial cells autophagy to promote metastasis. Cell Death Dis 2019;10:956.

116.Xie Y, Bagby TR, Cohen MS, et al. Drug delivery to the lymphatic system: importance in future cancer diagnosis and therapies. Expert Opin Drug Deliv 2009;6:785-92.

117. Oussoren C, Storm G. Liposomes to target the lymphatics by subcutaneous administration. Adv Drug Deliv Rev 2001;50:143-56.

118. Chida T, Miura Y, Cabral H, et al. Epirubicin-loaded polymeric micelles effectively treat axillary lymph nodes metastasis of breast cancer through selective accumulation and $\mathrm{pH}$-triggered drug release. J Control Release 2018;292:130-40.

119.Li X, Dong Q, Yan Z, et al. MPEG-DSPE polymeric micelle for translymphatic chemotherapy of lymph node metastasis. Int J Pharm 2015;487:8-16.

120.De Koker S, Cui J, Vanparijs N, et al. Engineering Polymer Hydrogel Nanoparticles for Lymph NodeTargeted Delivery. Angew Chem Int Ed Engl 2016;55:1334-9.

121. Fankhauser M, Broggi MAS, Potin L, et al. Tumor lymphangiogenesis promotes $\mathrm{T}$ cell infiltration and potentiates immunotherapy in melanoma. Sci Transl Med 2017;9:eaal4712.

122. Karnezis T, Farnsworth RH, Harris NC, et al. CCL27/ CCL28-CCR10 Chemokine Signaling Mediates Migration of Lymphatic Endothelial Cells. Cancer Res 2019;79:1558-72.

123.He Y, Rajantie I, Pajusola K, et al. Vascular endothelial cell growth factor receptor 3-mediated activation of lymphatic endothelium is crucial for tumor cell entry and spread via lymphatic vessels. Cancer Res 2005;65:4739-46.

124. Hirakawa S, Brown LF, Kodama S, et al. VEGF-C-induced lymphangiogenesis in sentinel lymph nodes promotes tumor metastasis to distant sites. Blood 2007;109:1010-7.

125. Hood JL, San RS, Wickline SA. Exosomes released by melanoma cells prepare sentinel lymph nodes for tumor metastasis. Cancer Res 2011;71:3792-801.

126. Li M, Lu Y, Xu Y, et al. Horizontal transfer of exosomal CXCR4 promotes murine hepatocarcinoma cell migration, invasion and lymphangiogenesis. Gene 2018;676:101-9.

127.Zhou CF, Ma J, Huang L, et al. Cervical squamous cell carcinoma-secreted exosomal miR-221-3p promotes lymphangiogenesis and lymphatic metastasis by targeting VASH1. Oncogene 2019;38:1256-68.

128. Harrell MI, Iritani BM, Ruddell A. Tumor-induced sentinel lymph node lymphangiogenesis and increased lymph flow precede melanoma metastasis. Am J Pathol 2007;170:774-86.

129. Peinado H, Zhang H, Matei IR, et al. Pre-metastatic niches: organ-specific homes for metastases. Nat Rev Cancer 2017;17:302-17.

130. Mashino K, Sadanaga N, Yamaguchi H, et al. Expression of chemokine receptor CCR7 is associated with lymph node metastasis of gastric carcinoma. Cancer Res 2002;62:2937-41.

131. Shields JD, Emmett MS, Dunn DB, et al. Chemokinemediated migration of melanoma cells towards lymphatics-a mechanism contributing to metastasis. Oncogene 2007;26:2997-3005.

132.Issa A, Le TX, Shoushtari AN, et al. Vascular endothelial growth factor-C and C-C chemokine receptor 7 in tumor 
cell-lymphatic cross-talk promote invasive phenotype. Cancer Res 2009;69:349-57.

133. Müller A, Homey B, Soto H, et al. Involvement of chemokine receptors in breast cancer metastasis. Nature 2001;410:50-6.

134. Kawada K, Hosogi H, Sonoshita M, et al. Chemokine receptor CXCR3 promotes colon cancer metastasis to lymph nodes. Oncogene 2007;26:4679-88.

135. Boyle ST, Ingman WV, Poltavets V, et al. The chemokine receptor CCR7 promotes mammary tumorigenesis through amplification of stem-like cells. Oncogene 2016;35:105-15.

136. Van de Velde M, Ebroin M, Durré T, et al. Tumor exposed-lymphatic endothelial cells promote primary tumor growth via IL6. Cancer Lett 2021;497:154-64.

137. Alitalo K. The lymphatic vasculature in disease. Nat Med 2011;17:1371-80.

138. Vlahakis NE, Young BA, Atakilit A, et al. The lymphangiogenic vascular endothelial growth factors VEGF-C and -D are ligands for the integrin alpha9beta1. J Biol Chem 2005;280:4544-52.

139.El-Chemaly S, Malide D, Zudaire E, et al. Abnormal lymphangiogenesis in idiopathic pulmonary fibrosis with insights into cellular and molecular mechanisms. Proc Natl Acad Sci U S A 2009;106:3958-63.

140. Koyama H, Kobayashi N, Harada M, et al. Significance of tumor-associated stroma in promotion of intratumoral lymphangiogenesis: pivotal role of a hyaluronan-rich tumor microenvironment. Am J Pathol 2008;172:179-93.

141. Fukumura D, Xavier R, Sugiura T, et al. Tumor induction of VEGF promoter activity in stromal cells. Cell 1998;94:715-25.

142.Liang P, Hong JW, Ubukata H, et al. Myofibroblasts correlate with lymphatic microvessel density and lymph node metastasis in early-stage invasive colorectal carcinoma. Anticancer Res 2005;25:2705-12.

143.Zhang Y, Tang H, Cai J, et al. Ovarian cancer-associated fibroblasts contribute to epithelial ovarian carcinoma metastasis by promoting angiogenesis, lymphangiogenesis and tumor cell invasion. Cancer Lett 2011;303:47-55.

144. Cadamuro M, Brivio S, Mertens J, et al. Platelet-derived growth factor-D enables liver myofibroblasts to promote tumor lymphangiogenesis in cholangiocarcinoma. J Hepatol 2019;70:700-9.

145. Wei R, Lv M, Li F, et al. Human CAFs promote lymphangiogenesis in ovarian cancer via the Hh-VEGF-C signaling axis. Oncotarget 2017;8:67315-28.

146. Wang C, Xu S, Tian Y, et al. Lysyl Oxidase-Like Protein 2 Promotes Tumor Lymphangiogenesis and Lymph Node
Metastasis in Breast Cancer. Neoplasia 2019;21:413-27.

147. Raju B, Haug SR, Ibrahim SO, et al. High interstitial fluid pressure in rat tongue cancer is related to increased lymph vessel area, tumor size, invasiveness and decreased body weight. J Oral Pathol Med 2008;37:137-44.

148.Planas-Paz L, Strilić B, Goedecke A, et al. Mechanoinduction of lymph vessel expansion. Embo $\mathrm{j}$ 2012;31:788-804.

149. Calvo F, Ege N, Grande-Garcia A, et al. Mechanotransduction and YAP-dependent matrix remodelling is required for the generation and maintenance of cancer-associated fibroblasts. Nat Cell Biol 2013;15:637-46.

150.Zhang K, Grither WR, Van Hove S, et al. Mechanical signals regulate and activate SNAIL1 protein to control the fibrogenic response of cancer-associated fibroblasts. J Cell Sci 2016;129:1989-2002.

151.Li R, Serrano JC, Xing H, et al. Interstitial flow promotes macrophage polarization toward an M2 phenotype. Mol Biol Cell 2018;29:1927-40.

152. Choi D, Park E, Jung E, et al. Piezo1 incorporates mechanical force signals into the genetic program that governs lymphatic valve development and maintenance. JCI Insight 2019;4:e125068..

153. Rockson SG. Lymphedema. Am J Med 2001;110:288-95.

154. Qin Y, He LD, Sheng ZJ, et al. Increased CCL19 and CCL21 levels promote fibroblast ossification in ankylosing spondylitis hip ligament tissue. BMC Musculoskelet Disord 2014;15:316.

155. Thomson CA, van de Pavert SA, Stakenborg M, et al. Expression of the Atypical Chemokine Receptor ACKR4 Identifies a Novel Population of Intestinal Submucosal Fibroblasts That Preferentially Expresses Endothelial Cell Regulators. J Immunol 2018;201:215-29.

156. Weber M, Hauschild R, Schwarz J, et al. Interstitial dendritic cell guidance by haptotactic chemokine gradients. Science 2013;339:328-32.

157.Förster R, Davalos-Misslitz AC, Rot A. CCR7 and its ligands: balancing immunity and tolerance. Nat Rev Immunol 2008;8:362-71.

158. Roberts EW, Broz ML, Binnewies M, et al. Critical Role for CD103(+)/CD141(+) Dendritic Cells Bearing CCR7 for Tumor Antigen Trafficking and Priming of T Cell Immunity in Melanoma. Cancer Cell 2016;30:324-36.

159. Förster R, Schubel A, Breitfeld D, et al. CCR7 coordinates the primary immune response by establishing functional microenvironments in secondary lymphoid organs. Cell 1999;99:23-33. 
160. Brinkman CC, Iwami D, Hritzo MK, et al. Treg engage lymphotoxin beta receptor for afferent lymphatic transendothelial migration. Nat Commun 2016;7:12021.

161. Thomas SN, Rohner NA, Edwards EE. Implications of Lymphatic Transport to Lymph Nodes in Immunity and Immunotherapy. Annu Rev Biomed Eng 2016;18:207-33.

162. Ulvmar MH, Werth K, Braun A, et al. The atypical chemokine receptor CCRL1 shapes functional CCL21 gradients in lymph nodes. Nat Immunol 2014;15:623-30.

163. Qu C, Edwards EW, Tacke F, et al. Role of CCR8 and Other Chemokine Pathways in the Migration of Monocyte-derived Dendritic Cells to Lymph Nodes. J Exp Med 2004;200:1231-41.

164. Mandala S, Hajdu R, Bergstrom J, et al. Alteration of lymphocyte trafficking by sphingosine-1-phosphate receptor agonists. Science 2002;296:346-9.

165.Pham TH, Baluk P, Xu Y, et al. Lymphatic endothelial cell sphingosine kinase activity is required for lymphocyte egress and lymphatic patterning. J Exp Med 2010;207:17-27.

166. Wei SH, Rosen H, Matheu MP, et al. Sphingosine 1-phosphate type 1 receptor agonism inhibits transendothelial migration of medullary $\mathrm{T}$ cells to lymphatic sinuses. Nat Immunol 2005;6:1228-35.

167. Singer, II, Tian M, Wickham LA, et al. Sphingosine1-phosphate agonists increase macrophage homing, lymphocyte contacts, and endothelial junctional complex formation in murine lymph nodes. J Immunol 2005; 175:7151-61.

168. Roozendaal R, Mempel TR, Pitcher LA, et al. Conduits Mediate Transport of Low-Molecular-Weight Antigen to Lymph Node Follicles. Immunity 2009;30:264-76.

169.Junt T, Moseman EA, Iannacone M, et al. Subcapsular sinus macrophages in lymph nodes clear lymph-borne viruses and present them to antiviral B cells. Nature 2007;450:110-4.

170.Sixt M, Kanazawa N, Selg M, et al. The conduit system transports soluble antigens from the afferent lymph to resident dendritic cells in the $T$ cell area of the lymph node. Immunity 2005;22:19-29.

171. Rantakari P, Auvinen K, Jäppinen N, et al. The endothelial protein PLVAP in lymphatics controls the entry of lymphocytes and antigens into lymph nodes. Nat Immunol 2015;16:386-96.

172.Kähäri L, Fair-Mäkelä R, Auvinen K, et al. Transcytosis route mediates rapid delivery of intact antibodies to draining lymph nodes. J Clin Invest 2019;129:3086-102.

173. Tamburini BA, Burchill MA, Kedl RM. Antigen capture and archiving by lymphatic endothelial cells following vaccination or viral infection. Nat Commun 2014;5:3989.

174. Kedl RM, Lindsay RS, Finlon JM, et al. Migratory dendritic cells acquire and present lymphatic endothelial cell-archived antigens during lymph node contraction. Nat Commun 2017;8:2034-.

175. Tewalt EF, Cohen JN, Rouhani SJ, et al. Lymphatic endothelial cells induce tolerance via PD-L1 and lack of costimulation leading to high-level PD-1 expression on CD8 T cells. Blood 2012;120:4772-82.

176. Rouhani SJ, Eccles JD, Riccardi P, et al. Roles of lymphatic endothelial cells expressing peripheral tissue antigens in CD4 T-cell tolerance induction. Nat Commun 2015;6:6771.

177. Dieterich LC, Ikenberg K, Cetintas T, et al. TumorAssociated Lymphatic Vessels Upregulate PDL1 to Inhibit T-Cell Activation. Front Immunol 2017;8:66.

178. Lane RS, Femel J, Breazeale AP, et al. IFN $\gamma$ activated dermal lymphatic vessels inhibit cytotoxic T cells in melanoma and inflamed skin. J Exp Med 2018;215:3057-74.

179. Hirosue S, Vokali E, Raghavan VR, et al. Steady-state antigen scavenging, cross-presentation, and CD8+ $\mathrm{T}$ cell priming: a new role for lymphatic endothelial cells. J Immunol 2014;192:5002-11.

180.Lukacs-Kornek V, Malhotra D, Fletcher AL, et al. Regulated release of nitric oxide by nonhematopoietic stroma controls expansion of the activated $\mathrm{T}$ cell pool in lymph nodes. Nat Immunol 2011;12:1096-104.

181. Nörder M, Gutierrez MG, Zicari S, et al. Lymph nodederived lymphatic endothelial cells express functional costimulatory molecules and impair dendritic cell-induced allogenic T-cell proliferation. FASEB J 2012;26:2835-46.

182. Podgrabinska S, Kamalu O, Mayer L, et al. Inflamed lymphatic endothelium suppresses dendritic cell maturation and function via Mac-1/ICAM-1-dependent mechanism. J Immunol 2009;183:1767-79.

183. Hara T, Shitara S, Imai K, et al. Identification of IL7-producing cells in primary and secondary lymphoid organs using IL-7-GFP knock-in mice. J Immunol 2012;189:1577-84.

184. Shinoda K, Hirahara K, Iinuma T, et al. Thy1+IL-7+ lymphatic endothelial cells in iBALT provide a survival niche for memory T-helper cells in allergic airway inflammation. Proc Natl Acad Sci U S A 2016;113:E2842-51.

185. Moussai D, Mitsui H, Pettersen JS, et al. The human cutaneous squamous cell carcinoma microenvironment is 
characterized by increased lymphatic density and enhanced expression of macrophage-derived VEGF-C. J Invest Dermatol 2011;131:229-36.

186. Brideau G, Mäkinen MJ, Elamaa H, et al. Endostatin overexpression inhibits lymphangiogenesis and lymph node metastasis in mice. Cancer Res 2007;67:11528-35.

187.Jung M, Ören B, Mora J, et al. Lipocalin 2 from macrophages stimulated by tumor cell-derived sphingosine 1-phosphate promotes lymphangiogenesis and tumor metastasis. Sci Signal 2016;9:ra64.

188. Dubey LK, Karempudi P, Luther SA, et al. Interactions between fibroblastic reticular cells and B cells promote mesenteric lymph node lymphangiogenesis. Nat Commun 2017;8:367.

189. Shin K, Kataru RP, Park HJ, et al. TH2 cells and their cytokines regulate formation and function of lymphatic vessels. Nat Commun 2015;6:6196.

190. Kataru RP, Kim H, Jang C, et al. T lymphocytes negatively regulate lymph node lymphatic vessel formation. Immunity 2011;34:96-107.

191. Chauhan SK, Jin Y, Goyal S, et al. A novel prolymphangiogenic function for Th17/IL-17. Blood 2011;118:4630-4.

192. Kubota Y, Takubo K, Shimizu T, et al. M-CSF inhibition selectively targets pathological angiogenesis and lymphangiogenesis. J Exp Med 2009;206:1089-102.

193. Religa P, Cao R, Bjorndahl M, et al. Presence of bone marrow-derived circulating progenitor endothelial cells in the newly formed lymphatic vessels. Blood 2005;106:4184-90.

194. Van't Hull EF, Bron S, Henry L, et al. Bone marrowderived cells are implicated as a source of lymphatic endothelial progenitors in human breast cancer. Oncoimmunology 2014;3:e29080.

195.Ran S, Montgomery KE. Macrophage-mediated lymphangiogenesis: the emerging role of macrophages as lymphatic endothelial progenitors. Cancers (Basel) 2012;4:618-57.

196. Bieniasz-Krzywiec P, Martín-Pérez R, Ehling M, et al. Podoplanin-Expressing Macrophages Promote Lymphangiogenesis and Lymphoinvasion in Breast Cancer. Cell Metab 2019;30:917-36.e10.

197.Murakami M, Zheng Y, Hirashima M, et al. VEGFR1 tyrosine kinase signaling promotes lymphangiogenesis as well as angiogenesis indirectly via macrophage recruitment. Arterioscler Thromb Vasc Biol 2008;28:658-64.

198. Cursiefen C, Chen L, Borges LP, et al. VEGF-A stimulates lymphangiogenesis and hemangiogenesis in inflammatory neovascularization via macrophage recruitment. J Clin Invest 2004;113:1040-50.

199. Cho CH, Koh YJ, Han J, et al. Angiogenic role of LYVE1-positive macrophages in adipose tissue. Circ Res 2007;100:e47-57.

200.Alitalo A, Detmar M. Interaction of tumor cells and lymphatic vessels in cancer progression. Oncogene 2012;31:4499-508.

201. Kadota K, Huang C, Liu D, et al. The clinical significance of the tumor cell D2-40 immunoreactivity in non-small cell lung cancer. Lung Cancer (Amsterdam, Netherlands) 2010;70:88-93.

202. Kadota K, Huang C, Liu D, et al. The clinical significance of lymphangiogenesis and angiogenesis in non-small cell lung cancer patients. Eur J Cancer 2008;44:1057-67.

203.Lin C, Song L, Liu A, et al. Overexpression of AKIP1 promotes angiogenesis and lymphangiogenesis in human esophageal squamous cell carcinoma. Oncogene 2015;34:384-93.

204. Kajita T, Ohta Y, Kimura K, et al. The expression of vascular endothelial growth factor $\mathrm{C}$ and its receptors in non-small cell lung cancer. Br J Cancer 2001;85:255-60.

205.Ming J, Zhang Q, Qiu X, et al. Interleukin 7/interleukin 7 receptor induce c-Fos/c-Jun-dependent vascular endothelial growth factor-D up-regulation: a mechanism of lymphangiogenesis in lung cancer. Eur J Cancer 2009;45:866-73.

206.Hu J, Cheng Y, Li Y, et al. microRNA-128 plays a critical role in human non-small cell lung cancer tumourigenesis, angiogenesis and lymphangiogenesis by directly targeting vascular endothelial growth factor-C. Eur J Cancer 2014;50:2336-50.

207.Wang Y, Yao Y, Liu H, et al. Itraconazole can inhibit malignant pleural effusion by suppressing lymphangiogenesis in mice. Transl Lung Cancer Res 2015;4:27-35.

208. Khromova N, Kopnin P, Rybko V, et al. Downregulation of VEGF-C expression in lung and colon cancer cells decelerates tumor growth and inhibits metastasis via multiple mechanisms. Oncogene 2012;31:1389-97.

209. Chen F, Takenaka K, Ogawa E, et al. Flt-4-positive endothelial cell density and its clinical significance in nonsmall cell lung cancer. Clin Cancer Res 2004;10:8548-53.

210.Donnem T, Al-Shibli K, Al-Saad S, et al. Prognostic impact of fibroblast growth factor 2 in non-small cell lung cancer: coexpression with VEGFR-3 and PDGF-B predicts poor survival. J Thorac Oncol 2009;4:578-85. 
211.Donnem T, Al-Saad S, Al-Shibli K, et al. Co-expression of PDGF-B and VEGFR-3 strongly correlates with lymph node metastasis and poor survival in non-small-cell lung cancer. Ann Oncol 2010;21:223-31.

212.Padera TP, Meijer EFJ, Munn LL. The Lymphatic System in Disease Processes and Cancer Progression. Annu Rev Biomed Eng 2016;18:125-58.

213.Hajrasouliha AR, Funaki T, Sadrai Z, et al. Vascular endothelial growth factor-C promotes alloimmunity by amplifying antigen-presenting cell maturation and lymphangiogenesis. Invest Ophthalmol Vis Sci 2012;53:1244-50.

214. Achen MG, Roufail S, Domagala T, et al. Monoclonal antibodies to vascular endothelial growth factor-D block its interactions with both VEGF receptor-2 and VEGF receptor-3. Eur J Biochem 2000;267:2505-15.

215.Kashima K, Watanabe M, Satoh Y, et al. Inhibition of lymphatic metastasis in neuroblastoma by a novel neutralizing antibody to vascular endothelial growth factor-D. Cancer Sci 2012;103:2144-52.

216. Atkins M, Jones CA, Kirkpatrick P. Sunitinib maleate. Nat Rev Drug Discov 2006;5:279-80.

217. Cives M, Strosberg JR. Gastroenteropancreatic Neuroendocrine Tumors. CA Cancer J Clin 2018;68:471-87.

218. Joensuu H. Sunitinib for imatinib-resistant GIST. Lancet 2006;368:1303-4.

219. Kodera Y, Katanasaka Y, Kitamura Y, et al. Sunitinib inhibits lymphatic endothelial cell functions and lymph node metastasis in a breast cancer model through inhibition of vascular endothelial growth factor receptor 3 . Breast Cancer Res 2011;13:R66.

220.van der Graaf WT, Blay JY, Chawla SP, et al. Pazopanib for metastatic soft-tissue sarcoma (PALETTE): a randomised, double-blind, placebo-controlled phase 3 trial. Lancet 2012;379:1879-86.

221. Motzer RJ, Haas NB, Donskov F, et al. Randomized Phase III Trial of Adjuvant Pazopanib Versus Placebo After Nephrectomy in Patients With Localized or Locally Advanced Renal Cell Carcinoma. J Clin Oncol 2017;35:3916-23.

222.Zhu G, Zhao M, Han Q, et al. Pazopanib Inhibits Tumor Growth, Lymph-node Metastasis and Lymphangiogenesis of an Orthotopic Mouse of Colorectal Cancer. Cancer Genomics Proteomics 2020;17:131-9.

223. Llovet JM, Ricci S, Mazzaferro V, et al. Sorafenib in advanced hepatocellular carcinoma. N Engl J Med 2008;359:378-90.
224.Procopio G, Verzoni E, Testa I, et al. Experience with sorafenib in the treatment of advanced renal cell carcinoma. Ther Adv Urol 2012;4:303-13.

225. Fleeman N, Houten R, Chaplin M, et al. A systematic review of lenvatinib and sorafenib for treating progressive, locally advanced or metastatic, differentiated thyroid cancer after treatment with radioactive iodine. BMC Cancer 2019;19:1209.

226. Grünwald V, Merseburger AS. Axitinib for the treatment of patients with advanced metastatic renal cell carcinoma (mRCC) after failure of prior systemic treatment. Onco Targets Ther 2012;5:111-7.

227. Atochina-Vasserman EN, Abramova E, James ML, et al. 1. Pharmacological targeting of VEGFR signaling with axitinib inhibits Tsc2-null lesion growth in the mouse model of lymphangioleiomyomatosis. Am J Physiol Lung Cell Mol Physiol 2015;309:L1447-54.

228. Curigliano G. Recent eUpdate on cabozantinib and nivolumab for first-line clear cell renal cancer to the ESMO Clinical Practice Guidelines on Renal Cell Carcinoma. Ann Oncol 2021;32:422-3.

229. Houvras Y, Wirth LJ. Cabozantinib in medullary thyroid carcinoma: time to focus the spotlight on this rare disease. J Clin Oncol 2011;29:2616-8.

230. Glen H. Lenvatinib therapy for the treatment of patients with advanced renal cell carcinoma. Future Oncol 2016;12:2195-204.

231. Thomas H. Liver cancer: Lenvatinib non-inferior to sorafenib for hepatocellular carcinoma. Nat Rev Gastroenterol Hepatol 2018;15:190.

232. Saif MW, Knost JA, Chiorean EG, et al. Phase 1 study of the anti-vascular endothelial growth factor receptor 3 monoclonal antibody LY3022856/IMC-3C5 in patients with advanced and refractory solid tumors and advanced colorectal cancer. Cancer Chemother Pharmacol 2016;78:815-24.

233. Goldman J, Rutkowski JM, Shields JD, et al. Cooperative and redundant roles of VEGFR-2 and VEGFR-3 signaling in adult lymphangiogenesis. FASEB J 2007;21:1003-12.

234. Takigawa H, Kitadai Y, Shinagawa K, et al. Multikinase inhibitor regorafenib inhibits the growth and metastasis of colon cancer with abundant stroma. Cancer Sci 2016;107:601-8.

235.Schmieder R, Hoffmann J, Becker M, et al. Regorafenib (BAY 73-4506): antitumor and antimetastatic activities in preclinical models of colorectal cancer. Int J Cancer 2014;135:1487-96.

236. Cortes J, Talpaz M, Smith HP, et al. Phase 1 dose-finding 
study of rebastinib (DCC-2036) in patients with relapsed chronic myeloid leukemia and acute myeloid leukemia. Haematologica 2017;102:519-28.

237.Park JS, Kim IK, Han S, et al. Normalization of Tumor Vessels by Tie2 Activation and Ang2 Inhibition Enhances Drug Delivery and Produces a Favorable Tumor Microenvironment. Cancer Cell 2016;30:953-67.

238. Monk BJ, Poveda A, Vergote I, et al. Final results of a phase 3 study of trebananib plus weekly paclitaxel in recurrent ovarian cancer (TRINOVA-1): Long-term survival, impact of ascites, and progression-free survival-2. Gynecol Oncol 2016;143:27-34.

239. Meyer M, Seetharam M. First-Line Therapy for Metastatic Soft Tissue Sarcoma. Curr Treat Options Oncol 2019;20:6.

240. Persaud K, Tille JC, Liu M, et al. Involvement of the VEGF receptor 3 in tubular morphogenesis demonstrated with a human anti-human VEGFR-3 monoclonal antibody that antagonizes receptor activation by VEGF-C. J Cell Sci 2004;117:2745-56.

Cite this article as: $\mathrm{He} M, \mathrm{He} Q$, Cai X, Chen Z, Lao S, Deng H, Liu X, Zheng Y, Liu X, Liu J, Xie Z, Yao M, Liang W, He J. Role of lymphatic endothelial cells in the tumor microenvironment-a narrative review of recent advances. Transl Lung Cancer Res 2021;10(5):2252-2277. doi: 10.21037/ tlcr-21-40
241.Neal J, Wakelee H. AMG-386, a selective angiopoietin1/-2-neutralizing peptibody for the potential treatment of cancer. Curr Opin Mol Ther 2010;12:487-95.

242.Harney AS, Karagiannis GS, Pignatelli J, et al. The Selective Tie2 Inhibitor Rebastinib Blocks Recruitment and Function of Tie2(Hi) Macrophages in Breast Cancer and Pancreatic Neuroendocrine Tumors. Mol Cancer Ther 2017;16:2486-501.

243. Grothey A, Blay JY, Pavlakis N, et al. Evolving role of regorafenib for the treatment of advanced cancers. Cancer Treat Rev 2020;86:101993.

244.Huang Y, Yuan J, Righi E, et al. Vascular normalizing doses of antiangiogenic treatment reprogram the immunosuppressive tumor microenvironment and enhance immunotherapy. Proc Natl Acad Sci U S A 2012;109:17561-6.

245. Cantelmo AR, Conradi LC, Brajic A, et al. Inhibition of the Glycolytic Activator PFKFB3 in Endothelium Induces Tumor Vessel Normalization, Impairs Metastasis, and Improves Chemotherapy. Cancer Cell 2016;30:968-85. 